Portland State University

PDXScholar

1990

\title{
An Investigation of the Relationship Between Training in Cooperative Learning and Teacher Job Satisfaction
}

Margaret Maloy Dutton

Portland State University

Follow this and additional works at: https://pdxscholar.library.pdx.edu/open_access_etds Let us know how access to this document benefits you.

\section{Recommended Citation}

Dutton, Margaret Maloy, "An Investigation of the Relationship Between Training in Cooperative Learning and Teacher Job Satisfaction" (1990). Dissertations and Theses. Paper 1142.

https://doi.org/10.15760/etd.1141

This Dissertation is brought to you for free and open access. It has been accepted for inclusion in Dissertations and Theses by an authorized administrator of PDXScholar. Please contact us if we can make this document more accessible: pdxscholar@pdx.edu. 


\title{
AN INVESTIGATION OF THE RELATIONSHIP BETWEEN TRAINING IN COOPERATIVE LEARNING AND TEACHER JOB SATISFACTION
}

by

MARGARET MALOY DUTTON

\begin{abstract}
A dissertation submitted in partial fulfillment of the requirements for the degree of

\author{
DOCTOR OF EDUCATION \\ in
} EDUCATIONAL LEADERSHIP
\end{abstract}

Portland State University 1990 
TO THE OFFICE OF GRĀDUATE STUDIES:

The members of the committee approve the dissertation of Margaret Maloy Dutton presented April 9, 1990.

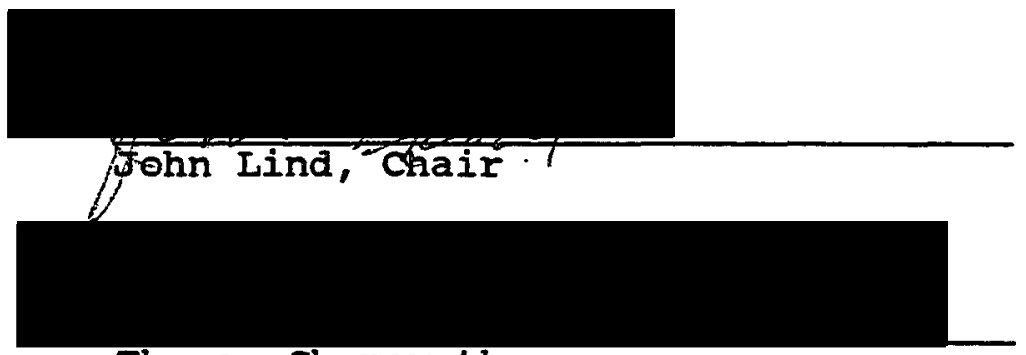

Thomas Chenoweth
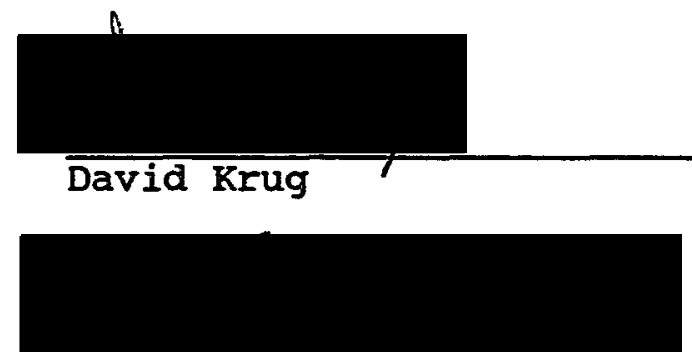

Anne Wax

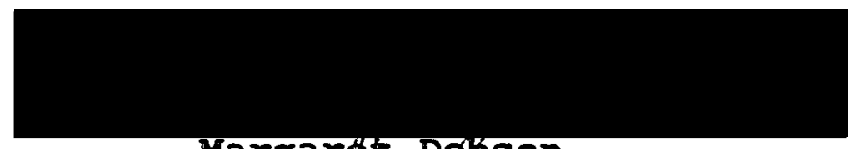

Margaret Døbson

APPROVED:

Robert B. Everhart, Dean, School of Education

C. William Savery, Vice Provost for Graduate Studies and Research 
AN ABSTRACT OF THE DISSERTATION OF Margaret Maloy Dutton for the Doctor of Education in Educational Leadership presented April 9, 1990.

Title: An Investigation of the Relationship Between Training in Cooperative Learning and Teacher Job Satisfaction.

APPROVED BY THE MEMBERS OF THE DISSERTATION COMMITTEE:

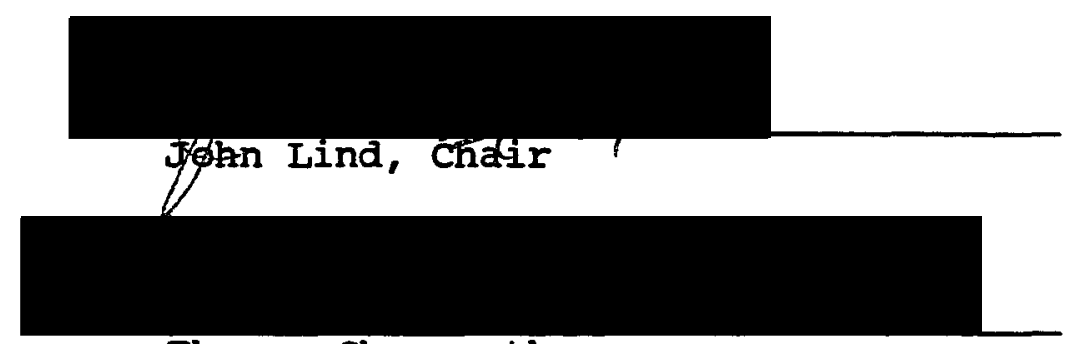
Thomas Chenoweth

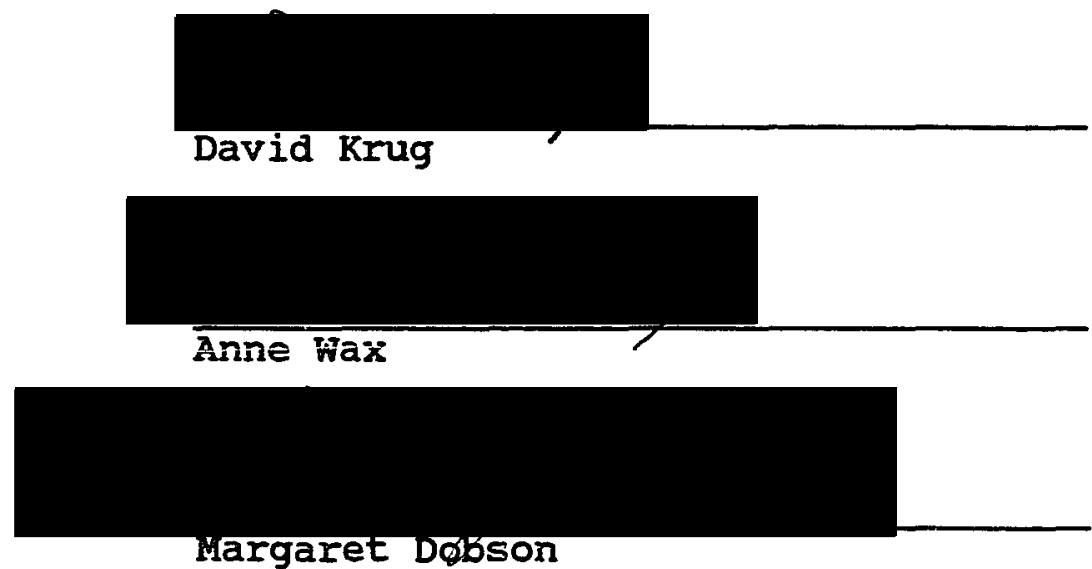

The research on cooperative learning has been conducted in terms of student achievement but little is known of how training in and use of cooperative learning 
affects teachers. The central purpose of this study was to examine the association between training in cooperative learning and teacher job satisfaction, with special attention to the subsets of collegiality and efficacy. A second purpose was to examine how levels of job satisfaction, efficacy, and collegiality vary as a function of the following training variables: (a) setting, (b) amount of use, (c) kind of training, (d) preparation for implementation, and (e) opportunity for skill maintenance. The research was conducted via questionnaire with 129 teachers responding, which was a response rate of $71 \%$. The questionnaire gathered data about training variables and included a 30-item Job Satisfaction Survey which had subscales: 10 questions on collegiality, 15 on efficacy, and 5 on overall job satisfaction. The validity of the Job Satisfaction Survey was established by pilot testing, by expert review of the questions, and by the use of an established survey as a bench mark for comparison. The research analysis involved examination of mean scores on the Job Satisfaction Survey and ANOVA technique to examine the significance of variables in training and levels of job satisfaction as well as the subsets of collegiality and efficacy.

Although the research did not reveal a significant relationship between training in cooperative learning and teacher job satisfaction, a significant relationship was 
found between several training variables and levels of satisfaction as well as collegiality and efficacy. The training variables found to be significantly associated with teacher efficacy were these: (a) use of cooperative learning at the level of seven or more times a week, (b) small group sharing and problem solving sessions for participants during training, (c) discussion with colleagues to maintain skills, and (d) the use of principal observation and feedback. The training variables found to be associated with collegiality were as follows: (a) the use of five different opportunities to maintain skills as opposed to three or fewer and (b) the use of peer coaching and feedback. Training variables associated with overall job satisfaction were: (a) small group sharing and problem solving sessions during training, (b) the use of five skill maintenance opportunities as opposed to three of fewer, and (c) the use of peer coaching and feedback. Given the results of this study, staff development specialists should structure training to include these significant variables as sources of collegiality and efficacy as well as overall job satisfaction of teachers. 


\section{ACKNOWLEDGEMENTS}

It is with deep appreciation that I express thanks to the many people who have been a part of my doctoral studies. Without their generous time and support, I could not have reached this goal. Several in the field of education have been an inspiration, especially the staff of the North Marion School District.

A special message of thanks to my doctoral committee who, from the beginning, challenged and encouraged me. Dr. John Lind, chairman, Dr. Tom Chenoweth, Dr. Margaret Dobson, Dr. David Krug, and Dr. Anne Wax have been most helpful.

Also, I would like to thank the administrators of the participating school district who were supportive throughout the study. For computer assistance I would like to thank Dr. Steve slater from the oregon Department of Education. For her encouragement every step of the way, I would like to thank Dr. Anne Wax.

Lastly, I wish to thank my family for patience and sense of perspective. The study is dedicated to my husband, Carl, to our daughter, Laura, and to my late parents who taught me the importance of courage and persistence in every endeavor. 
TABLE OF CONTENTS

PAGE

ACKNOWLEDGEMENTS . • . . . . . . . . . . . . . . . iii

LIST OF TABLES. . . . . . . . . . . . . . . . . . viii

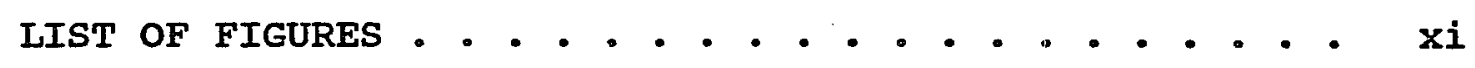

CHAPTER

I INTRODUCTION. . . . . . . . . . . . . . 1

Background. . . . . . . . . . . . 2

Efficacy Defined
Link Between Efficacy and Job
Satisfaction
Collegiality Defined
Link Between Collegiality and
Job Satisfaction
Overall Job Satisfaction
Staff Development Training
Variables
Summary of Training Variables

Statement of the Problem. . . . . . . 13

Purpose of the Study. . . . . . . . . 14

Research questions. . . . . . . . 15

Research Hypotheses . . . . . . . 16

significance of the study . . . . . . . 17

Limitations of the study. . . . . . . 19

Selection of the Population

Use of a Written Survey for Data Collection

Caution with Generalization of the Findings

Summary of Chapter I. . . . . . . 20 
PAGE

II REVIEW OF THE LITERATIRE. . . . . . . . . . 22

Introduction. . . . . . . . . . . 22

Cooperative Learning. . . . . . . . 22

Cooperative Learning Defined

Historical Perspective

Current Interest in Cooperative

Learning

Training in Cooperative Learning and

School Change . . . . . . . . .

Isolation Norm

Cooperative Norm

Training in Cooperative Learning and Teacher Joi Satisfaction. . . . . .

Role of Conversation and shared Language

Role of Personal Power

Studies of Teacher Job Satisfaction. . . 40

Summary of the Literature Review. . . . 42

III METHODOLOGY . . . . . . . . . . . . . 44

Introduction. . . . . . . . . . . 44

Development of the Survey Instrument. . . 44

Definition of Subscales . . . . . . 47

Validity of the Instrument. . . . . . 48

Final Administration of the Survey. . . . 53

Selection of subjects

Data Collection . . . . . . . . . 55

Summary of Methodology. . . . . . . 59

IV RESEARCH FINDINGS . . . . . . . . . . 60

Introduction. . . . . . . . . . 60 
PAGE

Population Characteristics. . . . . . 60

Procedure for Analysis. . . . . . . . 61

Findings on Questions 1A, 1B, and 1C. . 63

Findings on questions 2A, 2B, and 2C. . 67

Training Variable 1: Setting

Training Variable 2: Amount of Use

Training Variable 3: Kind of Training

Training Variable 3: Kind of Training Compared with Training Variable 2: Amount of Use

Feedback from a Qualified Observer: $13 \mathrm{E}$ and Training Variable \#2: Amount of Use

Training Variable 4: preparation for Implementation

Training variable 4: Preparation for Implementation compared with Training Variable 2: Amount of Use

Training Variable 5: Opportunities for skill Maintenance

Training Variable 5: Opportunities for Skill Maintenance Compared with Training Variable 2: Amount of Use

Summary of the Findings . . . . . . . 98

Research Questions 1A, 1B, and $1 \mathrm{C}$

Research Questions 2A, 2B, and $2 \mathrm{C}$

Summary of the Results. . . . . . . 101

V SUMMARY, CONCLUSIONS, AND RECOMMENDATIONS. - 103

Introduction. . . . . . . . . . 103

Summary of the study. . . . . . . . 103

Teacher Efficacy

Teacher Collegiality

overall Job Satisfaction 
vii

PAGE

Conclusions . . . . . . . . . . 108

Efficacy

Collegiality

Overall Job Satisfaction

Recomnendations for Educational Practice. 113

Recommendations for Further Research. . . 116

Replication of the study

REFERENCES. . . . . . . . . . . . . . 120

APPENDICES

A

Survey Instruments. . . . . . . . . 125

B

Correspondence. . . . . . . . . . . 138 


\section{IIST OF TABLES}

TABLE

PAGE

I Training Variables Under Study . . . . . . 45

II Job Satisfaction Subscales . . . . . . 48

III First Field Test . . . . . . . . . . 51

IV Job Satisfaction Surveys by Dutton and

Perko. . . . . . . . . . . 53

$\mathrm{V} \quad$ Details on Administration of the Survey. . . 57

VI Subscales of the Job Satisfaction Survey . . 63

VII Item 6G: Training in Cooperative Learning - 65

VIII Item 7 Regrouped: Hours of Training in Cooperative Learning .. . . . . . 66

IX Item 12: Amount of Use (Collapsed to Three Levels). . . . . . . . . . . 69

X ANOVA for Amount of Use and Efficacy . . . 70

XI Scheffé F-Test for Amount of Use and Efficacy ....... . . . . . 70

XII 13A-E: Kind of Training (Average Collapsed) . . . . . . . . . . . 71

XIII Item 13C: Group Sharing . . . . . . . 72

XIV ANOVA for 13C: Group Sharing and Efficacy . . . . . . . . . . 73

XV ANOVA for 13C: Group Sharing and Job Satisfaction . . . . . . . . . . 73

XVI 13A-E: Kind of Training (Collapsed) and Use Per Week . . . . . . . . . . . 74

XVII ANOVA for 13A-E: Kind of Training and Use Per Week . . . . . . . . . . . 75 
XVIII 13E: Feedback and 12: Amount of Use (Collapsed)... . . . . . . . . . 76

XIX ANOVA for 13E: Feedback and 12: Amount of Use (Collapsed). . . . . . . . . . . 77

XX Item 14: Preparation for Implementation and Use Per Week .. . . . . . . . 79

XXI ANOVA for Quality of Preparation and Amount of Use . . . . . . . . . . . . . . 79

XXII Fisher Test for Quality of Preparation for Implementation and Amount of Use... 80

XXIII Opportunities for Skill Maintenance (Collapsed). . . . . . . . . . . 81

XXIV ANOVA for Number of Opportunities for skill Maintenance and Collegiality . . . . . .

XXV

ANOVA for Number of Opportunities for Skill Maintenance and overall Job Satisfaction . . . . . . . . . . .

XXVI Fisher Test for Number of Skill Maintenance Opportunities and Collegiality . . . . 84

XXVII Fisher Test for Number of skill Maintenance Opportunities and overall Job Satisfaction . . . . . . . . . .

XXVIII Summary of Significant Comparisons Between Skill Maintenance Opportunities and Levels of Collegiality, Efficacy, and Job Satisfaction . . . . . . . . .

XXIX Item 15A: Discussion with Colleagues and Efficacy .... . . . . . . . . 86

XXX ANOVA for 15A: Discussion with Colleagues and Efficacy . . . . . . . . . . 86

XXXI Item 15B: Peer Coaching and Collegiality. . 87

XXXII ANOVA for 15B: Peer coaching and Collegiality . . . . . . . . . . . 87

XXXIII Item 15B: Peer Coaching and Job Satisfaction . . . . . . . . . . 88 
XXXIV ANOVA for 15B: Peer coaching and Job Satisfaction ............. 88

XXXV Item 15D: Principal Observatior/Feedback and Efficacy . . . . . . . . . 89

XXXVI ANOVA for 15D: Principal Observation/ Feedback and Efficacy. . . . . . . 89

XXXVII Opportunities for skill Maintenance and Use Per Week . . . . . . . . . . 90

XXXVIII ANOVA Between Number of skill Maintenance Opportunities and Use Per Week... . . 91

XXXIX Fisher Test for Number of Skill Maintenance Opportunities and Amount of Use. . . . 92

XI Summary of Significant Comparisons Between Skill Maintenance opportunities and Amount of Use. . . . . . . . . . 93

XII Item 15C: Staff Meeting Discussion and Use Per Week . . . . . . . . . . . 95

XLII ANOVA for 15C: Staff Meeting Discussion and Use Per Week... . . . . . . 95

XIIII Item 15D: Principal Observation/Feedback and Use Per Week . . . . . . . . . 96

XIIV ANOVA for 15D: Principal Observation/ Feedback and Use Per Week. . . . . . 96

XLV Item 15E: Assistance from Staff Development Personnel and Use Per Week . . . . . 97

XLVI ANOVA for 15E: Assistance from Staff Development Personnel and Use Per Week. - 97

XLVII Summary of Significant Comparisons Between Training Variables and Levels of Collegiality, Efficacy and Job Satisfaction ........... . . 102 


\section{LIST OF FIGURES}

1. Graph Showing Preparation for Implementation and Use of cooperative Learning Per Week . . . . . . . . 80

2. Graph Showing opportunities for Skill Maintenance and Use of Cooperative Learning Per Week . . . . . . . . . 92 
CHAPTER I

\section{INTRODUCTION}

A teaching technique which is rapidly gaining popularity and momentum is cooperative learning. Cooperative learning principles include team building, communication skills, inclusiveness, and supportive interaction among the learners. Summarized in the words of Johnson and Johnson (1982), students "have to invest themselves in each other's learning if they want to be successful" (p. 10).

The research on cooperative learning has been conducted in terms of student achievement and social growth, with successful gains documented in both areas (slavin, 1985). But little is known of how training in and use of cooperative learning procedures affects teachers. As is the case with many educational reforms, the application for students has received most of the attention, whereas the impact on teachers has generally been overlooked.

As a staff development topic, cooperative learning has a large repertoire of affective dimensions such as helping, encouraging, teaming, and supporting. An essential feature of training is actual cooperative experiences by teachers, with participation in collegial settings where problems, 
successes, and planning can be shared (Johnson, Johnson, \& Holubec, 1988). Training in cooperative learning and subsequent use in the classroom may carry over into staff working relationships producing change in the levels of communication, collegiality, self-confidence, and ultimately in overall job satisfaction. Factors which satisfy teachers and the subsequent attitudes they hold may be carried into the classroom and reflect in their work with students (Ashton \& Webb, 1986). For this reason, the possible relationship between staff development in cooperative learning and teacher job satisfaction deserves investigation.

\section{BACKGROUND}

Teachers are the key to school improvement; their efforts and commitment are indispensable to student success (Rosenholtz, 1985). But effort and good intentions are not enough. The skills needed by teachers become increasingly complex as societal problems such as drugs, broken families, and homelessness impact the schools. Staff development is important for skill development. It is equally important so that teachers can develop collegiality, maintain a sense of efficacy, and experience satisfaction in their work. In the words of Perko (1985), "Modern organizational theory recognizes job satisfaction of the staff as a key to effectiveness and change or renewal within the organization" 
(p. 6). Elements of training in cooperative learning would appear to affect both collegiality and efficacy, as well as overall job satisfaction; therefore, the relationship should be investigaṫed.

\section{Efficacy Defined}

Fullan (1982) believes that "one of the most pressing needs in education is for teachers to have the opportunity to restore their sense of confidence, meaning, and efficacy" (p. 129). Ashton (1984) defines efficacy as feeling capable, powerful, and self-confident. Furthermore, the development of efficacy makes teachers "believe in themselves as powerful forces in their classrooms, able to help students learn and thrive" (Sparks, 1988, p. 117). As Joyce, Hersh, and McKibbin (1983) state, efficacy is a "sense of potency, and it is the psychic energy needed for the relentless and persevering effort required to maintain high task orientation" (p. 26). Additionally, efficacious teachers hold the belief that they can make improvements and, consequently, are receptive to professional development and willing to try innovation (Ashton, Webb, \& Doda, 1983). A sense of efficacy makes teachers believe they have the power within to change their world where it encompasses their classrooms and students (Dembo \& Gibson, 1985). For the purposes of this scudy, efficacy is defined as a strong sense of personal power and influence. Holding 
this belief, efficacious teachers tend not to give up and instead will try a variety of approaches with hard-to-reach students. They look especially for ways to give low achieving and discouraged students even a small taste of success, because success itself serves as a source of selfesteem and motivation (Bloom, 1978). Efficacious teachers see their actions as causal and influential in the achievement of their students.

\section{Iink Between Efficacy and} Job Satisfaction

The link between efficacy and job satisfaction is strongly established by research.

Fuller, Wood, Rapoport, and Dornbusch (1982) state:

- . research on motivation in a variety of organizations indicates the importance of individual efficacy. - . efficacy appears related to job commitment and satisfaction, performance on work tasks, and low employee turnover. (p. 12)

Fuller et al. also state:

Within school settings, empirical research is beginning to reveal that perceived efficacy significantly influences student performances and organizational outcomes. (p. 11)

Smylie (1988) underscores the importance of efficacy to educational change:

- . the greater at teacher's personal efficacy and certainty of practice, the more likely that teacher will be to change practice as a result of staff development. (p. 11)

Sparks (1988) supports Smylie's statement:

When teachers have a stronger self-efficacy, they are more likely to have confidence to take risks and 
to experiment, and thus are move likely to improve. (p. 112)

Adams and Bailey (1989) offer this advice.

Therefore, when principals concentrate on building teacher self-efficacy, they are doing two things; they are contributing to teacher job satisfaction, and providing for more effective learning in the classroom through enhanced teacher motivation. ( $p$. 46)

Gibson and Dembo (1984) refer to a study by Berman and McLaughlin on the evaluation of Title III projects in which they found efficacy a determinant of teacher change:

- . the most important characteristic determining the effectiveness of change-agent projects was teachers' sense of efficacy--a belief that teachers can help even the most difficult or unmotivated students. (p. 569)

Rosenholtz (1985, 1987) discusses school conditions where there is an absence of personal efficacy on the part of teachers. The result is alienation, withdrawal, high absenteeism, and the "ultimate manifestation of withheld services, disengaged teachers" (1985, p. 357). Lack of efficacy and the resulting alienation is described by Gecas and Schwalbe (1983) as "the dissociation of self from the products of work activity" (p. 79). Maloy and Jones (1987) state that success or failure lies within personal attitudes and when the work environment is dominated by isolation, teachers may opt to play it safe and "detach emotionally from school and change" (p. 23).

The need for efficacy is summarized in Bandura's definition: efficacy determines "how much effort people 
will expend, and how long they will persist in the face of obstacles and aversive experiences" (cited in Trentham, Silvern, \& Brodgan, 1985, p. 80). Because it is a strong sense of efficacy which enables teachers not just to survive and endure, but to prevail and flourish in their efforts with students, staff development in cooperative learning must be examined in terms of how it contributes to and sustains efficacy, and ultimately job satisfaction.

\section{Collegiality Defined}

Collegiality is defined as working together, reducing isolation, and finding help an encouragement from peers (Joyce et al., 1983; Little, 1982). Groups of teachers may work together to help each other gain competence, solve problems, plan new strategies, and simply let off steam (Johnson et al., 1988). Joyce et al. (1983) emphasize that school improvement "requires collective activity" (p. 69) to overcome the norms of isolation and homeostasis which hold sway against change. Additionally, Joyce et al. stress the need teachers have for ongoing support from peers which bolsters confidence and maintains motivation in order to withstand the erosion of power, feelings of isolation, and setbacks encountered in the classroom. Ashton (1984) and Lortie (1975) emphasize that group support is vital to maintaining motivation and to sustaining a sense of 
confidence in the face of uncertainty, hostility, and failure.

Collegiality, as defined for this study, is the process of interacting with colleagues for the purpose of helping them in their professional work as teachers. Collegial exchange may take the form of reflection on the past, brainstorming of ideas, or perhaps a planned course of action. The collegial process, because it draws on the resources and expertise of peers, can be a source of professional strength and empowerment.

\section{Link Between Collegiality} and Job Satisfaction

The link between collegiality and job satisfaction is established by research. Cohen and his colleagues (cited in Fullan, 1982) studied open-spaced schools; their study shows:

- . increased teacher-teacher collaboration occurs and in come cases is strongly related to job satisfaction. (p. 122)

Fullan (1982) states that teachers: - . need to have one-on-one and group opportunities to receive and give help, and more simply to converse about the meaning of change. ( $p$. 121)

Fullan further points out that teachers will look for: - . satisfaction from the intellectual and practical benefits of helping, getting help, and sharing. (p. 122)

Johnson, Johnson, and Holubec (1988) echo Fullan's views: 
When teachers become too isolated . . considerable job dissatisfaction results. Isolation is a major contributing factor to the low morale and lack of continuing collegial growth. There are a number of studies that have concluded that teachers are less satisfied with the quality of their work-lives and more likely to experience problems with their jobs than are most Americans. (p. 27)

Smylie (1988) writes:

- . cooperative and supportive working relationships among teachers have been found to be related significantly to teacher change associated with implementation of school innovations. (p. 9)

Rosenholtz (1985) describes a successful school as one which is task-oriented and includes intellectual sharing. She makes this recommendation:

Frequent conversations about instructional practices and how to improve them, then, increases the likelihood that student achievement will be viewed as a highly salient aspect of school life. (p. 366)

Sparks (1988) emphasizes that getting teachers together regularly in small instructional support groups to examine their own teaching can be a powerful vehicle for change. Such groups provide "a safe environment for teachers to discuss their concerns and victories" (p. 117) and to gain confidence to try new methods.

The importance of collegiality is well summarized in the words of Rosenholtz (1989), "Ironically, as teachers contemplate the enormous challenges before them . . . perhaps the best weapon they could wield against uncertainty lies in colleagues, . - within their own schools" (p. 69). Because collaboration and peer support are powerful factors in job satisfaction, staff development in cooperative 
learning should be examined in terms of how it contributes to collegiality.

\section{Overall Job Satisfaction}

Perko (1985) describes job satisfaction as a broad term used to refer to attitudes and feelings about work. Herzberg (cited in Sergiovanni, 1984) provided a theory in which he separated intrinsic and extrinsic factors in job satisfaction. He called the intrinsic factors motivators and identified five: achievement, recognition, work itself, responsibility, and advancement. Herzberg believed these five factors to be associated with satisfaction, but their absence is not part of dissatisfaction. In a second classification he placed hygienic factors: items such as salary, working conditions, and technical supervision. These he believed to be associated with dissatisfaction if absent, but they are not a part of job satisfaction. For this study, the term overall job satisfaction refers to general intrinsic attitudes and feelings about the job of teaching. The study will place special emphasis on collegiality and efficacy as two subsets of overall job satisfaction.

Staff Development Training Variables

Not all efforts in teacher training are equally successful. One of the biggest dilemmas in educational 
reform is described by Fullan (1982) as "too much well intentioned 'ad-hoc-ism'--the use of single, segmented solutions" (p. 66), which are never integrated into the system. From personal experience, this researcher knows it is fairly common for teachers to attend "one-shot" workshops of the lecture method, by themselves or perhaps with a colleague, with no follow-up opportunity to share or apply the learning. This type of staff development is costly, and quickly forgotten. We are reminded that "a great many efforts to improve schools, even when very well funded and approved by the public, had encountered great difficulty and achieved very low levels of implementation" (Joyce \& Showers, 1988, p. 87).

The presence of supportive staff development may provide hope and reassurance for teachers, as well as a source of job satisfaction. Based on the recommendations of Fullan (1982), Joyce and Showers (1988), Joyce et al. (1983), and sparks (1983), the following training variables should be considered: (a) setting, (b) amount of use (practice), (c) kind of training, (d) preparation for implementation, and (e) opportunity for skill maintenance. The outline which follows provide further details on the training variables recommended in the research; the outline was used to design the questions in Part I of the questionnaire used in the study.

Variable \#1--Setting: 
1. With or without colleagues

2. With or without the principal

3. In-district or out-of-district trainers

Variable \#2--Amount of use with students (practice)

Variable \#3--Kind of training; presence or absence of:

1. Background theory

2. Modeling and demonstration

3. Small group sharing sessions

4. Cooperative learning activities during class

5. Feedback during early implementation

Variable \#4--Preparation for implementation:

Variable \#5--Opportunities for skill maintenance; presence or absence of:

1. Discussion with colleagues

2. Peer coaching and feedback

3. Staff meeting discussion

4. Principal observation and feedback

5. Assistance from staff development personnel

Summary of Training Variables

setting, the first variable on the list, refers to both the location and the people involved in a staff development effort. Much of the recent literature advocates school-imbedded or site-based training with school or district colleagues taking classes together, ideally with the principal. This format is looked upon as building the 
sense of ownership which is necessary for change to occur and to last (David, 1989; Deal, 1984; Joyce et al., 1983). In-district trainers hold the additional credibility of "really knowing how it is here."

The variable of practice or amount of use, refers to application of the new method. Many innovations result in very low levels of implementation, or application by only a few staff members. Without practice, the processes of coaching, refining, and adjusting cannot take place. The result is short-lived innovations, soon ignored. In the words of Joyce et al. (1983) "educational habit has been lethal to many reforms" (p. 63).

The components of training, variable \#3, are based mostly on the work of sparks (1983). She recommends the development of philosophical acceptance of a new method by providing background theory. The small group sharing sessions are seen as a safe environment in which to share setbacks and admit the need for help. Three of the training components reduce isolation by setting up collegial activity. They are: (a) small group sharing sessions, (b) cooperating learning activities during class, and (c) feedback during early implementation.

Variable \#4, preparation for implementation, is one which seems to be frequently ignored. It is a summary of the five training components in Variable \#3. Variable \#4 asks for teacher's overall impression of how well the 
training prepared them to begin using cooperative learning in the classroom.

Opportunities for skill maintenance, variable \#5, consist of five activities which are follow-up after training. Each one requires collegial involvement and cannot occur in isolation. The skill maintenance activities are based on the work of Fullan (1982), Joyce and Showers (1988), and Joyce et al. (1983). Discussion with colleagues not only provides an opportunity to problem solve, but to share testimonials and literally "sell" the benefits of the innovation to others. Peer coaching is a means of obtaining non-threatening help, particularly important during the early stages when new methods may feel awkward, and present unanticipated problems. Staff meeting discussion, principal observation, and help from staff development personnel are opportunities to give the innovation visibility and prestige, and to recognize and encourage the others who show willingness to change. To ensure teacher motivation and commitment, maintenance activities need to be ongoing.

\section{STATEMENT OF THE PROBLEM}

The pleasure and satisfaction of teaching pales in the face of its complexities and adversities. In his book, The Imperiled Profession, Duke (1984) describes the job of teaching during the past two decades as an impossible profession caught in a downward spiral. Changes in the 
public's expectations, and in the students themselves, are among several reasons for growing feelings of disillusionment and inadequacy among teachers. The current educational setting is one of discouraged educators facing almost overwhelming problems; problems which contribute to low morale, hopelessness, and job dissatisfaction.

Good staff development which fosters sustained professional growth "may be one of the few sources of revitalization and satisfaction left for teachers" (Fullan, 1982, pp. 118-119). While schools are expanding staff development programs in an effort to improve and bring about change, there is a lack of research about the impact of training on the teachers themselves. Yet it is they who are the key to any successful change effort. Cooperative learning is a topic with great potential for impact on teacher job satisfaction as well as efficacy and collegiality. Therefore, effects of training in cooperative learning need to be examined.

\section{PURPOSE OF THE STUDY}

A review of the literature supports the view that teacher job satisfaction is a predictor of teacher change and willingness to grow (Fullan, 1982; Smylie, 1988). This is the primary reason for investigating staff development which may contribute to job satisfaction. 
This study's first purpose was to examine the relationship between training in cooperative learning and level of job satisfaction. The primary focus is to compare job satisfaction scores of teachers who have taken cooperative learning with the scores of those who have not had the training. The job satisfaction score will be based on efficacy, collegiality, and overall satisfaction.

A second purpose was to examine the relationship between variables in the training process and levels of satisfaction, collegiality, and efficacy. The training variables under study are these: (a) setting, (b) amount of use, (c) kind of training, (d) preparation for implementation, and (e) opportunities for collegial support in skill maintenance.

The study was not intended to establish a causal ink, but rather to identify a possible significant relationship between training in cooperative learning and job satisfaction.

\section{RESEARCH QUESTIONS}

1. A. Do teachers trained in cooperative learning have a higher level of overall job satisfaction than teachers who have not had the training?

1. B. Do teachers trained in cooperative learning have a higher level of collegiality than teachers who have not had the training? 
1. C. Do teachers trained in cooperative learning have a higher level of efficacy than teachers who have not had the training?

2. A. Is there a relationship between the training variables and level of overall job satisfaction?

2. B. Is there a relationship between the training variables and level of collegiality?

2. c. Is there a relationship between the training variables and level of teacher efficacy?

\section{RESEARCH HYPOTHESES}

Research Hypothesis \#1A: Teachers who experience training in cooperative learning will have a higher level of overall job satisfaction than teachers who do not experience the training.

Research Hypothesis \#1B: Teachers who experience training in cooperative learning will have a higher level of collegiality than teachers who have not experienced the training.

Research Hypothesis \#1C: Teachers who experience training in cooperative learning will have a higher level of efficacy than teachers who have not had the training.

The independent variable selected for the study is training in cooperative learning. Hypothesis 1A, 1B, and $1 \mathrm{C}$ will be measured by mean scores on the Job Satisfaction Survey. 
Research Hypothesis \#2A: There is a significant difference in overall job satisfaction between teachers who experience different training variables in cooperative learning.

Research Hypothesis \#2B: There is a significant difference in collegiality between teachers who experience different training variables in cooperative learning. Research Hypothesis \#2C: There is a significant difference in efficacy between teachers who experience different training variables in cooperative learning.

Hypotheses $2 \mathrm{~A}, 2 \mathrm{~B}$, and $2 \mathrm{C}$ are tested by performing ANOVA on each of the independent variables with the mean scores on job satisfaction, collegiality, and efficacy. The independent variables are: (a) setting, (b) amount of use (practice), (c) kind of training, (d) preparation for implementation, and (e) opportunities for collegial support in skill maintenance.

\section{SIGNIFICANCE OF THE STUDY}

Cooperative learning, as well as all staff inservice, should be examined for its contribution to and effect on the teachers themselves. It is their attitude and commitment that is central to school improvement; therefore, research on teacher job satisfaction is highly important. since efficacy is defined as the teacher characteristic with the most consistent relationship to student achievement (Ashton, 
1984); practicing administrators need to know more about the development of efficacy. The same need exists for building collegiality, which plays such a powerful role in teacher motivation and endurance.

Further investigation of teacher job satisfaction is often recommended. Lortie (1975) calls for research on the issue of power, or efficacy in teachers. A similar need is echoed by Sparks (1988) who asks for further study of training processes which relate to efficacy. Given the importance of efficacy as a predictor of teacher change, Smylie (1988) advocates further investigation of the topic. Trentham et al. (1985) ask how teachers can be trained to be more efficacious. The need for collegial support among teachers is strongly advocated (Ashton, 1984; Joyce et al., 1983; Lortie, 1975); but, as with efficacy, there is an absence of research about the impact of training on either factor and on overall job satisfaction. A growing body of teacher satisfaction data will be helpful to education leaders and provide implications for practice as they address the challenges in today's schools.

A second important implication for practice from this study will be collecting and adding to the knowledge base of information about selected training processes. Conducted in the real setting of a large local district, the research will gather information useful in the selection and design of subsequent programs for teacher inservice. Training 
itself has a great bearing on teacher acceptance and use of innovation. Without teacher acceptance, many new methods never survive beyond the training period; they become lightly implemented and never talked about. Identification of effective training variables which contribute to high implementation and to collegiality, efficacy, and overall satisfaction will be an important outcome of the study.

\section{IIMITATIONS OF THE STUDY}

The limitations of the study include: (a) the selected population, (b) use of a written survey for data collection, and (c) caution with generalization of the findings. A brief description of each limitation follows.

Selection of the Population

The study was conducted in a suburban school district known for an active staff development program and a high level of teacher involvement. This population sample may be unusually high in job satisfaction as well as in collegiality and efficacy, compared to other districts.

Use of a Written Survey for Data Collection

A written survey procedure has built-in limitations. One may be an inclination not to fill it out, especially when it is several pages in length. Written surveys often arrive simultaneously with other extra paperwork, which may 
discourage participation. Finally, the findings may be specific to the respondents' interpretation of the questions; in other words, there is no verbal clarification or explanation of any item.

\section{Caution with Generalization} of the Findings

There are a number of ways in which job satisfaction can be thought of and measured. The entire range of job satisfaction, all attitudes and feelings about work, cannot be covered in one survey even though some of the questions are very general in content. The findings, therefore, may be specific to this study sample of respondents and to their perceptions of job satisfaction factors specific to the survey •

\section{SUMMARY OF CHAPTER I}

The study of teacher job satisfaction is a vital issue in the context of today's school problems. This investigation of the relationship between cooperative learning and job satisfaction will proceed with a review of the literature followed by a presentation of the study's methodology and findings. Data were collected by means of a written survey. The first question to be investigated was whether training in cooperative learning--no training, little training, or extensive training--is associated with 
overall job satisfaction as well as the subsets of collegiality and efficacy.

The second question relates to training variables which were investigated to see which ones may be associated with satisfaction, collegiality, and efficacy. It must be understood that the training variables are not synonymous with cooperative learning itself. The training variables are elements of staff development instruction and can be included in other course work such as classroom management, learning styles, or ITIP (instructional theory into practice). The population selected for this investigation will have experienced diverse programs in their cooperative learning training; different formats, different content emphasis, and a variety of follow-up activities. The second purpose of the study is to examine how levels of teacher job satisfaction, collegiality, and efficacy vary among teachers who experience different training variables in cooperative learning. 
CHAPTER II

REVIEW OF THE LITERATURE

\section{INTRODUCTION}

The literature review is divided into four sections. The first is a review of cooperative learning which will describe its features and place it in perspective with individualistic and competitive procedures. Reasons behind the current interest in cooperative methods are reviewed in this section.

The second section is a review of teacher training in cooperative learning. The role of the training process in reducing isolation and building collaboration is examined. The establishment of a cooperative norm then becomes an avenue toward organizational changes which lead to greater collegiality, efficacy, and job satisfaction. The third section reviews this process.

Finally, studies on teacher job satisfaction will be summarized along with findings which are relevant to the survey instrument developed for this investigation.

\section{COOPERATIVE LEARNING}

This section includes a definition of cooperative learning and traces its historical development. 
Cooperative Learning Defined

Cooperative learning is defined by slavin (1982) as "instructional methods in which students of all levels of performance work together in small groups toward a common goal" (p. 6). Slavin's definition further states:

The essential feature of cooperative learning is that the success of one student helps other students to be successful. This is just the opposite of the traditional classroom, in which competition for grades and for other rewards means that one student's success may reduce the changes of another's success. (p. 6)

In addition to positive goal interdependence, cooperative learning principles include group cohesion, team building, inclusiveness, communication skills, and supportive interaction among the learners (Graves \& Graves, 1985). Summarized in the words of Johnson and Johnson (1982), students "have to invest themselves in each other's learning if they want to be successful" (p. 10).

Cooperative learning in the classroom requires careful planning and organization. The teacher must structure the cooperative activity based on these assumptions: (a) skills of cooperation must be taught, (b) peer interaction is essentiai, and (c) peer interaction must be constructive (Johnson, Johnson, Holubec, \& R:YY, 1984) - Before a lesson begins, the teacher must establish two kinds of objectives; first, the academic learning and second, the collaboration skill. Collaboration skills are social skills and must be directly taught, not assumed. Examples are skills such as 
taking turns, using language which encourages and not using put-downs, and managing disagreement. The collaboration skills are often reinforced by asking students to produce a single product or report and giving a grade or recognition to the entire group, not to individual members (Johnson \& Johnson, 1982; Johnson et al., 1984).

Researchers (Graves \& Graves, 1985; Kagan, 1985; Slavin, 1985) have made the following recommendations for building cooperative groups:

1. Group membership must be heterogeneous and inclusive. In practice this procedure mainstreams everyone; the handicapped, the low achiever, and all ethnic groups.

2. Group members should have shared responsibilities and shared leadership, with rotation of roles. In practice this places empowerment within the reach of every group member at some time.

3. Group members should exchange talents and skills, with individuals taking on a quasi-teacher role of tutoring or coaching when appropriate. In practice this builds shared responsibility for and investment in the success of one another.

The same authors emphasize that the goal is not to totally replace individualistic and competitive methods; rather, it is to substantially increase the use of cooperation. All three models have important value. 
Historical Perspective

Individual and competitive methods of instruction and learning have dominated American education for the past half century (Johnson et al., 1984; Kagan, 1985). Our country has prized rugged individualism and competition. While some school children, especially those who are talented, athletic, or outgoing, may find themselves members of groups or teams, many students miss out on cooperative experiences (Brandt, 1987). A common theme in teacher directions has been "Do your own work" or "Let's see who can get the highest grade"; admonitions which set the tone for individualism and competition.

A 1929 study was conducted by Julius Maller (cited in Slavin, 1985) after which he stated the following:

The frequent staging of contests, the constant emphasis upon the making and breaking of records, and the glorification of the heroic individual achievement and championship in our present educational system lead toward the acquisition of the habit of competitiveness. The child is trained to look at the members of the group as constant competitors and urged to put forth a maximum effort to excel them. The lack of practice in group activities and community projects in which the child works with his fellows for a common goal precludes the formation of habits of cooperativeness and group loyalty. (p. 365)

The lack of practice in group activities mentioned by Maller applies to teachers as well as students and has been noted by Fullan (1982), Joyce and Showers (1988), and Lortie (1975) 
A more recent description of a typical classroom was supplied by Towson (1985):

- . children compete . . in a system that works well for academically proficient children. For children who are more often "loosers" than "winners" in the ongoing classroom competition, failure to obtain tangible rewards is coupled with the perception of negative peer opinions to create a self-fulfilling cycle of academic failure and low self-esteem. If most of the "loosers" are members of one ethnic group and most of the "winners" are members of another, negative interethnic attitudes -. result. (p. 269)

Towson's statement summarizes a major challenge in contemporary education; the public's growing expectation of educational success for all students.

Current Interest in

Cooperative Learning

During the past decade, cooperative learning has received wide attention. The literature review revealed two major challenges in today's schools which account for the growing interest: (a) the crisis in student socialization, along with the closely related need for extensive personal safety education, and (b) the public's expectation of educational success for all students. Cooperative learning is not new; it has been used for many years in settings such as laboratories, discussion groups, team sports, and other special projects. What is new is the current application of cooperative learning procedures to all grade levels and all subjects as a regular part of instruction in basic skills (Slavin, 1982). The use of learning teams in the academic 
areas has been advocated by Glasser (1986) who described the motivation students experience as members of teams in nonacademic areas. As an example, he discussed the needfulfilling structure of a basketball team in which both the strong and weak players sense power, belongingness, and fun. Glasser advocated teamwork in the academic subjects where the same need exists for self-fulfillment and satisfaction in learning.

Teachers of our decade work with a growing number of children who lack training in constructive socialization; Johnson et al. (1984) has labeled the situation a crisis and cited the increase in juvenile crime, suicide and behavior disorders. The absence of a nurturing, stable home life along with less adult supervision means more aloneness for children. Preparation of positive social skills will need to be provided at school by teachers. Cooperative learning provides a curriculum for building supportive peer relationships.

As a nation we are coming to realize the necessity of working together, and including everyone, as "the keystone to building and maintaining stable marriages, families, careers, and friendships" (Johnson \& Johnson, 1982, p. 11) our well-being as a country may depend on the concept of a kinder, gentler nation of people who can work collaboratively and rely upon one another for help (Bush 
cited in Apple, 1989). The challenge which teachers face is stated by Kagan (1985):

Cooperative experiences in schools are the only viable way to systematically socialize future generations to meet the needs presented by an increasingly urban, technological, and interdependent workforce. (p. 368)

closely related to the crisis in socialization is the growing personal safety curriculum. Today's teachers are expected to help provide training in personal assertiveness so that children can and will say no to a variety of threats to their own well-being; threats such as drug use, gang membership and sexual abuse. All personal safety programs are based on effective communication, especially on refusal skills. Teachers find cooperative learning methods a necessity in teaching this curriculum.

A second challenge in today's field of education is the result of a perception change; our public has come to expect and demand educational success for all students. Much of the effective schools research of the past decade supports the belief that the label of "slow learner" can be removed under optimum learning conditions (Ashton, 1984; Bloom, 1978; Brookover et al., 1982). In other words, a student's learning potential is not a fixed entity, but rather an ever-changeable entity which is influenced by environmental factors such as kind and amount of schooling. The notion that intelligence is a stable, unchanging score has been challenged in particular by Bloom who viewed 
mastery of subject matter as a function of time and favorable learning conditions, not IQ score.

With the growing view of individual differences in learning as "manmade and accidental rather than fixed in the individual" (Bloom, 1978, p. 564), the alteration of learning conditions becomes essential, and the role of the teacher more powerful. Teacher behavior is looked upon as potent and influential; teachers are seen as causal agents in student achievement (Ashton, 1984).

The belief that repeated success and self-confidence seem to "confer upon . . . students a type of immunization" (Bloom, 1978, p. 564) against failure speaks to the responsibility schools have toward children who have been labeled slow learners. The cumulative impact of practices such as tracking and reducing the level of instruction for some students sends powerful messages to the learner. In Bloom's words, "Teachers rarely expect most of the students to learn well--and the students come to expect the teacher's view of them and their learning capabilities" (p. 571). The procedures of cooperative Iearning such as heterogeneous grouping, shared leadership, peer teaching, and supportive interaction among the learners are among the methods teachers can use to place success within the reach of all students (Graves \& Graves, 1985).

In summary, two enormous challenges have fostered the current interest in cooperative learning: the crisis in 
student socialization and the public's expectation of success for all pupils. As today's teachers grapple with tough challenges, a "sink or swim" approach is not conducive to a satisfying work environment. More than ever before, teaching can be a lonely and disheartening job; the students, and especially the teachers themselves, need to invest in the success of one another. In the face of bigger challenges each year, we need school environments that are uplifting, full of caring and cooperation.

\section{TRAINING IN COOPERATIVE LEARNING AND SCHOOI CHANGE}

A recurrent theme in the school change literature is that any attempt to bring about change must address the needs of the teachers themselves. "Essentially, effective staff development programs bring about change and growth in teachers, just as effective instructional programs bring about change and growth in students" (Joyce \& Showers, 1988, p. 115). Johnson and Johnson (1982) stated that "Cooperation among school staff is as important as cooperation among students" (p. 10). The norms of a school, the climate and the working relationships, will be transmitted to students, whether planned or not, and those norms can be positive or negative (Joyce et al., 1983). 
Isolation Norm

Lortie (1975) described the cellular, or egg carton, design of schools which fostered physical aloneness, with cumulative years of isolation in which no common technical vocabulary developed and no community of peer support evolved. The isolation norm has also been described by Joyce et al. (1983); they pictured the school organization as so loosely coupled that it is possible, and commonplace in some instances, for teachers to remain left alone throughout their entire careers. Joyce et al. and Hersh (1985) described the power of organizational homeostasis as forces which keep things the same and hold off any innovations which would threaten a comfortable and predictable worklife.

Social norms in a school can evolve into strong role patterns in which only two or three influential staff members achieve the powerful role of gatekeepers and actually block and screen any attempts at improvement. Negative gatekeepers may protect the status quo through ridicule of new ideas and of those who dare to bring them up in conversation. These behaviors can block staff development plans and are lethal to motivation and job satisfaction of other members. A "clique of gatekeepers" (Herzberg, 1987, p. 191) has the power to weaken and prevent new ideas from being implemented. Innovation and change are seen as threatening and unless strong collaborative norms 
are in place, changes do not survive. Homeostatic forces, the informal social pressures which maintain established patterns and habits of the school, are usually more powerful than innovative forces (Joyce et al., 1983). With this challenge in mind, Hersh (1985) made the following recommendation:

Any attempt to create a better environment for education will have to decrease isolation, increase cooperative planning. . . Unless cooperative activity becomes the norm, homeostatic forces reign and the move toward increased organizational efficacy is stifled. (p. 24)

\section{Cooperative Norm}

The essential feature of staff inservice in cooperative learning is actual cooperative experience by the teachers and participation in small group settings where successes and problems can be shared. Johnson and Johnson (1980) cautioned against inservice training formats which rely heavily on lectures, entertainment, and flashy media; none of which unlock the door to successful and lasting innovation. It is the process of collegial relationships which sets the stage for a receptive climate. Teamwork is a process; "you cannot successfully tutor an individual teacher into a sense of joint purpose" (Johnson \& Johnson, 1980 , p. 2). The concept of "actual doing" as opposed to "learning about" is essential in cooperative learning training because it is the collaboration process which 
breaks the isolation norm and sets the process of cooperation in motion.

Cooperative learning trainers often begin by randomly assigning teachers to dyads; it may be the first time ever for some pairs of colleagues to sit next to each other, and certainly the first time to discuss their work. This is especially true of the combination of a negative gatekeeper and a highiy enthusiastic teacher, or of teachers with different assignments, such as first and fifth grades. The use of small groups, two to six in size, has been conducive to building mutual support and interaction; this holds true for staff members of different ages, backgrounds, and special areas of expertise (Sparks, 1988). In the cooperative learning experience, team members who may never have exchanged more than a few words, are directed to work through an assignment, together. They may need to receive instruction and help from a peer, share and divide a task, receive correction and help from a peer, and reach agreement on the appearance of the final product (Johnson \& Johnson, 1980). The collaborative setting requires face-to-face interaction; teachers must talk to each other. The need for collective action in order for change to survive and flourish is strongly emphasized in the literature. Joyce and Showers (1988) described the need for faculty members to understand that decisions can be binding on the group with everyone obligated to comply. They adied, 
"The norm in many faculties (an unwritten, but powerful rule) has been to select directions and then allow those persons who do not want to participate "off the hook" (p. 142). This is one of the reasons collective action has not been the norm. Initiatives are greatly weakened by partial participation. Lortie (1975) advocated collegial responsibility with teams held accountable for producing results. Brookover et al. (1982) concurred, stating that change implemented on a collective basis was less threatening. Fullan (1982) recommended that everyone must be implicated for change to survive.

In summary, cooperative learning activities make it difficult for individuals or groups to remain negative gatekeepers to change. The training requires teacher participants to work together in physical proximity and to communicate, thereby breaking the barriers of isolation. The process sets in motion the possibility for change to take place and increases the probability of collective involvement. Groups of teachers must be heterogeneous. Membership should include the newcomer and the veteran; the enthusiastic and the reluctant. It is collective involvement that is required to overcome homeostasis and allow new methods to become transferred into existing patterns in the classroom. 
TRAINING IN COOPERATIVE LEARNING AND TEACHER JOB SATISFACTION

Concern for building job satisfaction was addressed by Deal (1984) who stated that main avenues for survival in public schools are to "hunker down, burn out, or leave" (p. 135). He prescribed this alternative: "improvement must be developed from within. It must arise from collective conversations, behavior, and spirit" (p. 136). Fullan (1982), a strong advocate of building job satisfaction through collaboration, provided this summary:

The more teachers experience the rewards of interaction the more they will use the criterion of professional contact and development--satisfaction from the intellectual and practical benefits of helping, getting help, and sharing with other teachers--as a measure of whether to become involved in innovation. And make no mistake about it, focused teacher interaction is essential to largescale change. (p. 122)

Role of Conversation and

Shared Lanquage

Cooperative group activities are a part of the training process for teachers in cooperative learning. The giving and getting which take place as teachers converse builds awareness of their own resources and facilitates supportive relationships among group members. The workplace becomes less threatening because shared conversation reveals that "no teacher is immune to classroom problems" (Rosenholtz, 1989, p. 45). This is a vital step toward job satisfaction. Once the truth is out that everyone has 
problems and no one has all the answers, it feels less threatening to mention difficulties (Sparks, 1988) . "If help seeking is potentially embarrassing or stigmatizing, it may prove threatening to people's self-worth, they will avoid self-disclosure" (Rosenholtz, 1989, p. 42). They may seek ways of doing so by withdrawing, covering up, refusing to use new methods, or even hiding behind some kind of counter-productive behavior such as ridicule. Feelings of guardedness may exist with teachers keeping up the appearance of being on top of every situation and acting as though they never need help (Johnson et al., 1988). The process of collaboration, even when modest in amount, begins to remove the need for avoidance behavior (Joyce et al., 1983). Teachers find an empathetic group in which it is safe to give voice to difficulties. Peers become a source of strength, information, and reassurance which makes teachers "less likely to succumb to the sense of helplessness" (Ashton, 1984, p. 31), enhancing their sense of well-being and satisfaction at work.

It is the spoken word which drives the behavior and spirit of change and innovation; the conversation in a collaborative setting builds shared vocabulary which becomes increasingly precise and concrete (Little, 1982). Cohesive plans are generated as teachers talk and publicly commit themselves to the ideas being discussed, another important step toward job satisfaction. When a teacher in a group 
gives voice to a commitment in the presence of colleagues, the teacher has programmed his/her own behavior; literally "talked themselves into it." As stated by Johnson and Johnson (1980), "the more teachers publicly coramit themselves to implement the material being presented, the more recognition and respect individuals will receive from colleagues for doing so" (p. 2). In the process of talking about an innovation, teachers have the opportunity to publicly commit themselves to the change and sustain the momentum needed to keep it alive (Maloy \& Jones, 1987). Peer communication builds collective buy-in and the pledge of support from staff members. The process develops change which is generated from within, not imposed from without.

To summarize, the training activities in cooperative learning break the barrier of privatism among teachers, giving educational change a chance to survive in a more receptive climate. Conversation with colleagues becomes a source of needed help and encouragement. A level of trust is built that opens the door to change and innovation.

\section{Role of Personal Power}

Training in cooperative learning emphasizes camaraderie and emotional support among peers; these human relations skills can sustain teacher confidence, selfesteem, and sense of personal power during vulnerable times, such as during the implementation of new methods or even 
when dealing with hostile students. A strong sense of personal power, or efficacy, helps teachers achieve a strong role definition of themselves as causal agents in the performance of their students; a belief which is strongly tied to job satisfaction (Gecas \& Schwalbe, 1983; Johnson \& Johnson, 1980; Smylie, 1988).

Ashton (1984) defined efficacy as the"extent to which teachers believe they have the capacity to affect student performance" (p. 28). Low efficacy teachers, through the use of less instruction, less interaction, less praise, and so on, may stigmatize some students who quickly see themselves and their capabilities as the teacher sees them. The teacher's sense of hopelessness or futility is invariably communicated to the student and subsequently becomes part of the student's self-concept (Bloom, 1978; Brookover et al., 1982). On the other hand, higher efficacy teachers tend to be more encouraging toward student, show willingness to teach all students in the class, use a variety of teaching strategies, and seem resolved not to accept student failure (Ashton \& Webb, 1986). Efficacious teachers were described by David Berliner (cited in Ashton \& Webb, 1986) as follows:

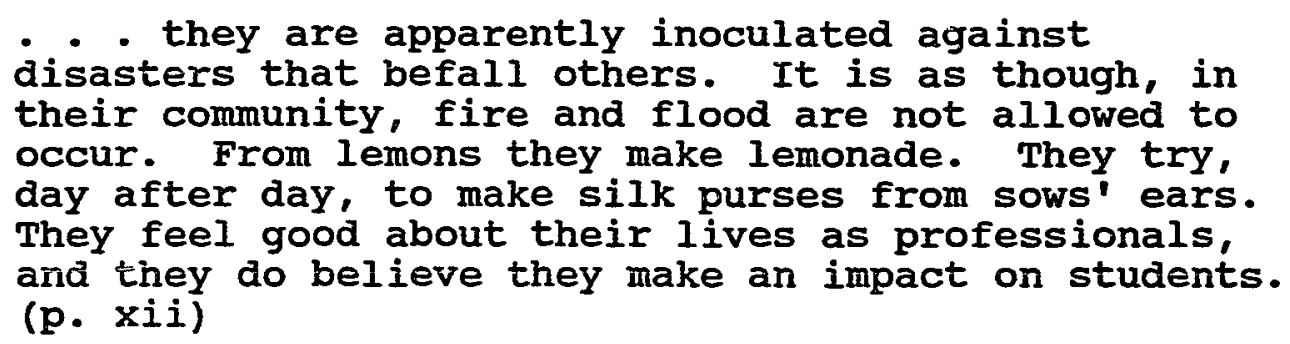


In addition to building personal power, or efficacy, the small group collaboration experiences which are part of training in cooperative learning foster willingness to try new methods. New teaching techniques often stumble during early application; they may feel awkward and require practice. It is during this phase that teachers are in need of ongoing supportive help through staff discussions, peer coaching, and feedback from observation. "If the climate is harsh and unforgiving of error" (Joyce et al., 1983, p. 87), innovation and change will be difficult; but a supportive work climate which nurtures the individual and the group will make change easier and most certainly contribute to mental well-being and job satisfaction. Johnson and Johnson (1980) stated that a sense of being able to handle any problems which come along during implementation resulted when a group of peers sat down together to problem solve. The small group sharing and problem solving built the confidence needed to risk innovation and withstand setbacks. In summary, training in cooperative learning provides a setting in which teachers can build supportive relationships with colleagues. In doing so, they develop their own sense of control and esteem and ultimately a survivor personality. With greater confidence comes a willingness to try innovation, and a greater feeling of job satisfaction. 
STUDIES OF TEACHER JOB SATISFACTION

Job satisfaction is a broad term used to refer to attitudes and feelings about work (Perko, 1985). It is a prevalent topic for research with a need for more exact measures in the educational setting (Gruneberg, 1979; Lester, 1987). Gruneberg defined job satisfaction as the "individual's emotional reactions to a particular job" ( $p$. 3) and he further stated that "when considering research on job satisfaction, it is important to bear in mind just how complex is the interpretation of research findings, given the multiplicity of ways in which it can be conceived and measured" (p. 3)

Several researchers have recommended that teacher job satisfaction become a priority concern of school administrators. Sergiovanni (1984, pp. 193-212) in his chapter on teacher satisfaction and motivation held that the "motivated teacher must become a high priority concern of principals" (p. 193). Drawing on the work of Herzberg and Maslow, Sergiovanni recommended teachers find satisfaction for intrinsic needs of "esteem, competence, achievement, autonomy, and self-actualization" (p. 206).

Echoing a similar interest in job satisfaction was Wax (1983) in her study of burnout in school administrators. Among the six subscales of burnout identified in her research, there are two which closely parallel the 
dimensions of collegiality and efficacy. They are: (a) relationships, defined as involvement with and acceptance by colleagues and (b) psycho-physical states, defined as overall mental, emotional, and physical vigor and resilience. Emotional vigor and resilience is an excellent description of efficacy as an optimistic frame of mind that knows "This, I can do." In a collegial setting, the mindset becomes "This, we can do."

A study by Kreis and Brockopp (1986) examined teacher job satisfaction in terms of only one construct: autonomy. These researchers relied heavily on past studies which point to the teacher's need for power, influence, and authority in their role in order to feel effective and causal in achieving success. Lester's (1987) study of teacher job satisfaction included nine constructs: supervision, colleagues, working conditions, pay, responsibility, work itself, advancement, security, and recognition.

At least two major studies of job satisfaction have been conducted in the Portland area during the past decade. One was done in a large suburban district by Leslie (1989). Her study surveyed teachers to draw from them the categories which had the greatest influence on their level of satisfaction. A category named "teacher decisions" ranked first, suggesting the need for locus of control and a strong role definition. The category seems parallel in meaning to the construct of efficacy. Leslie advocated for a conscious 
effort on the part of administration to address the causes of dissatisfaction and to promote satisfaction. Because teachers are fundamental to school improvement, principals must find ways to give them a "sense of their own importance and expertise" (p. 22).

A second study on job satisfaction was done by Perko (1985). Her research identified the factors teacher respondents said contributed most to their degree of satisfaction. The results, in rank order were as follows:

1. Interpersonal relations with students

2. Sense of achievement

3. Teaching as kind of work (work itself)

4. Interpersonal relations with fellow teachers

5. Opportunities to help others

The construct of collegiality was identified in item 4 and efficacy is closely related to items 2, 3, and 5 from Perko's findings. Among her recommendations for further research was investigation of staff development which contributes to job satisfaction of teachers.

SUMMARY OF THE LITERATURE REVIEW

The literature review indicates that staff development in cooperative learning with its affective strategies of sharing, encouraging, and helping in collegial settings has potential for impact on the teachers themselves and on their work environment. In the face of the many challenges 
teachers confront in today's classrooms, staff development is important not only for building their skills but also as an avenue for building job satisfaction. Research on the affective effects of training is lacking; it is an area of needed investigation addressed by this study.

From the literature review, both collegiality and efficacy emerge as important factors in job satisfaction. In this study, collegiality is defined as communication among colleagues about professional matters. Furthermore, it is a step toward sharing, helping, and planning in a collaborative setting; thereby contributing to the success and satisfaction of fellow teachers. The barrier of isolation is broken which opens the possibility for ongoing support among peers and the survival of innovation. Efficacy, defined in this study as a strong sense of personal power, helps teachers develop a strong role definition as causal agents in the success of their students.

The literature review builds a strong case for the importance of continued research on teacher job satisfaction, and the subsets of collegiality and efficacy, since each is a predictor of successful change efforts and ultimately of greater student achievement. 
CHAPTER III

METHODOLOGY

INTRODUCTION

This chapter describes the study's research procedures. This was a quantitative study using a questionnaire to gather data on two categories of information. Part I of that questionnaire looked at demographic data and information about training variables. Part II related to the teacher attitude under investigation which was overall job satisfaction as well as the factors of collegiality and efficacy. The completed questionnaires provided a data base which was used to analyze a possible relationship between level of job satisfaction and training in cooperative learning. The following sections are included in this chapter: (a) Development of the survey Instrument, (b) Definition of Subscales, (c) Validity of the Instrument, (d) Final Administration of the Survey, and (e) Data collection.

DEVELOPMENT OF THE SURVEY INSTRUMENT

Part I of the instrument began with questions on demographic data, followed by items 6-15 designed to collect 
information about training (see Appendix A). Question 6 was the stem question from which respondents divided into two categories, those who had training in cooperative learning and those who had not. Questions 7 and 8 gathered information about amount and level of training. questions 9-15 asked for information on training variables important to effective staff development; variables based on the recommendations of Fullan (1982), Joyce and Showers (1988), Joyce et al., (1983), and Sparks (1983). The table which follows outlines the recommendations and was used in writing items 9-15.

TABLE I

TRAINING VARIABLES UNDER STUDY

Variables

Question

\#1 Setting:

a) With or without colleagues 9

b) With or without the principal 10

c) In-district or out-of-district trainers 11

\#2 Amount of use with students (practice) 12

\#3 Kind of training; presence of absence of: 13

a) Background theory

b) Modeling and demonstration

c) Small group sharing sessions

d) Cooperative learning activities during class

e) Feedback during early implementation

\#3 Preparation for implementation

\#5 Opportunities for skill maintenance; presence or absence of:

a) Discussion with colleagues

b) Peer coaching and feedback

c) Staff meeting discussion

d) Principal observation and feedback

e) Assistance from staff development personnel 
Part II of the questionnaire was a 30-item Job Satisfaction Survey. Most of the items were drawn from existing scales and modified for use in this study. Established job satisfaction surveys were not suitable for two reasons. One problem was length. A large number of questions can discourage participation entirely or cause those who do participate to revert to getting it done quickly rather than thinking through each question. A second problem with existing scales was content; there was a lack of items on both collegiality and efficacy. This seems ironic because the research strongly points to these two dimensions as powerful factors in job satisfaction. Existing scales tended to survey a broad range of items in such areas a salary, working conditions, and supervision. A set of questions was needed to gather in-depth data on both collegiality and efficacy with attention to the subcomponents of each as defined in the literature review. The existing scales which were used as resources were these:

1. Administrator Role Perception Inventory (Wax, 1983)

2. Purdue Teacher Opinionaire (Scott-Miller, 1984)

3. Teacher Efficacy Scales (Gibson \& Dembo, 1984)

4. Teacher Job Satisfaction Questionnaire (Lester, 1987) 
5. Teacher Opinion Survey (National study of School Evaluation, 1981)

6. Teacher Study Questionnaire (Perko, 1985)

A total of 30 questions were used; 5 on overall job satisfaction, 10 on collegiality, and 15 on efficacy. Items for collegiality and efficacy were sorted into subscales, or components, identified in the literature. This process required several sessions of resorting (each question was on a card) to establish fit and belongingness in a subscale. In the final form, items were intermixed to prevent respondents from recognizing a "family" of questions and then trying to be consistent in their responses.

\section{DEFINITION OF SUBSCAIES}

The Job Satisfaction Survey tested collegiality, efficacy, and overall job satisfaction.

Collegiality had two subscales: peer support and collaboration, defined below.

Peer support: The activities of listening, sharing, helping, coaching, and encouraging in order to contribute to the success of a colleague.

Collaboration: The interaction of two or more colleagues, who are physicaily in the presence of one another as opposed to being isolated.

Efficacy had three subscales: power, confidence, and willingness to innovate; defined below. 
Power in the role of teacher: The teacher's belief that what he/she does makes a significant difference in student achievement.

Confiderice in working with students: The teacher's belief that he/she is capable of helping each student learn. Willingness to innovate: The teacher's openness to try new approaches in the classroom.

The subscales and item numbers are shown in Table II.

TABLE II

JOB SATISFACTION SUBSCALES

Subscale Items

Peer support (collegiality)

$1,7,13,19,25$

collaboration (collegiality)

$2,8,14,20,26$

Power (efficacy)

$3,9,15,21,27$

Confidence (efficacy)

$4,10,16,22,28$

willingness to innovate (efficacy)

$5,11,17,23,29$

Overall job satisfaction

$6,12,18,24,30$

\section{VALIDITY OF THE INSTRUMENT}

Three procedures were conducted to establish the validity of the Job Satisfaction survey. They were: (a) expert review of the questions followed by revisions where 
recommended, (b) field testing, and (c) use of an established survey for a bench mark.

An expert review of the survey was done by Dr. Anne Wax and Dr. John Lind. Dr. Wax is Director of Instruction and Staff Development for a nearby school district. In addition she serves as a lecturer in Portland state University's Department of Educational Policy, Foundations, and Administrative studies (EPFA) teaching Principles of Educational Research and Supervision and Evaluation of Instruction. Dr. Lind is the former Chairperson of EPFA at Portland state University. In addition he is a Professor of Education and teaches classes in statistics.

The recommendations of Dr. Wax and Dr. Lind resulted in the revision of four questions, as follows:

Original version--question number 4: what is your estimate of how many students in your class feel included?

Revision--question number 4: Please estimate: In your class how many students really have a sense of belonging, of feeling included by other students?

The revision provided a more precise definition of inclusiveness by adding the phrase "sense of belonging." Original version--question number 10: How successful are you in meeting the intellectual needs of your students? Revision--question number 10: How successful are you in meeting the academic needs of your students? 
The revision uses the word "academic" in place of "intellectual;" the reason for the change was that teachers measure academic level more often than intellectual level. They feel less certain about intellectual level.

Original version--question number 22: How successful are you in meeting the socialization needs of your students? Revision--question number 22: How successful are you in teaching your students the skills they need for working together?

The revision replaces the term "socialization" with the phrase "skills of working together;" the phrase is a more precise definition for cooperation among students.

Original version--question number 23: Are you able to get through by trying various techniques, to even the most difficult students?

Revision--question number 23: Recall a recent situation in which a student had trouble learning. How many techniques did you try in order to "get through" to him or her?

The revision solved two problems. The first version implied only difficult students need various techniques for learning. The revision corrected this by referring to a "student who has trouble." secondly, the phrase "how many techniques" is more precise and gives more information than the term "various techniques." 
The second procedure used to establish validity of the instrument was field testing. The first field test was conducted in late March. A group of nine teachers in a nearby suburban district completed the entire questionnaire. As a result of this first testing, several questions in both Part I and Part II underwent revisions based on verbal feedback and notes from participants. The results of the first field test with nine respondents are shown in Table III.

TABLE III

FIRST FIELD TEST

\begin{tabular}{cll}
\hline Respondent \# & $\begin{array}{c}\text { Job } \\
\text { Satisfaction Score }\end{array}$ & $\begin{array}{l}\text { Amount of Training in } \\
\text { Cooperative Learning }\end{array}$ \\
\hline 1 & 108 & None \\
2 & 115 & None \\
3 & 117 & None \\
4 & 128 & None \\
5 & 122 & $1-5$ hours \\
6 & 122 & $1-5$ hours \\
7 & 131 & $6-10$ hours \\
8 & 123 & $26-30$ hours \\
9 & 141 & $30+$ hours \\
\hline
\end{tabular}


The job satisfaction score was determined by assigning a numerical value to each letter: $A=5, B=4, C=3, D=2$, and $E=1$. The total for each respondent had to fit between 30, the lowest possible score and 150, the highest possible score. This small population sample showed a pattern of higher scores in job satisfaction for respondents who had some training in cooperative learning, with the exception of teacher \#4.

The Job Satisfaction Survey, Part II of the instrument, was again field tested during April of 1989, this time against an established instrument. A total of 24 teachers from area school districts participated. All 24 teachers took two tests on job satisfaction. One was the 30-item test developed by this investigator.

The second was a 30-item test with questions taken from the extensive survey used by Perko (1985) for her dissertation on job satisfaction. The purpose was to check the validity of the current test by using the Perko survey as a benchmark. After selecting questions, they were grouped into subscales as shown in Table IV. The Spearman correlation of the 24 paired observations on the variables of Dutton and Perko was a statistic of 0.858 . Therefore, when the newly developed Job Satisfaction Survey (Dutton) was compared with the a previously validated survey (Perko), a high correlation was found. 
TABLE IV

JOB SATISFACTION SURVEYS BY DUTTON AND PERKO

\begin{tabular}{llc}
\hline Subscale & $\begin{array}{c}\text { Survey \#1 } \\
\text { Item Numbers } \\
\text { Dutton study }\end{array}$ & $\begin{array}{c}\text { Survey \#2 } \\
\text { Item Numbers } \\
\text { Perko Study }\end{array}$ \\
\hline $\begin{array}{l}\text { Peer support } \\
\text { Collaboration }\end{array}$ & $1,7,13,19,25$ & $6,12,18,24$ \\
$\begin{array}{l}\text { Power } \\
\text { Confidence }\end{array}$ & $3,8,14,20,26$ & $5,11,17,23$ \\
$\begin{array}{l}\text { Willingness to } \\
\text { innovate }\end{array}$ & $4,10,16,22,28$ & $3,9,15,21$ \\
$\begin{array}{l}\text { Overall job } \\
\text { satisfaction }\end{array}$ & $5,11,17,23,29$ & $2,8,14,20$ \\
\end{tabular}

FINAL ADMINISTRATION OF THE STUDY

Selection of subjects

The population selected for the study was the entire elementary classroom teaching staff of a local suburban district; a total of 181 certificated staff members employed during the 1988-1989 school year. This population sample was appropriate for several reasons. There would be an adequate sample even if a considerable number did not participate. This situation had to be anticipated because of the time of year (May) and the fact that this questionnaire most certainly would be only one of a number 
of forms teachers are asked to complete. The population sample included members of two groups, those with many hours of cooperative learning training and those with little or no training.

The school district itself was of special interest for this study because approximately half of its nine elementary schools had on-site cooperative learning taught by district staff development personnel during the past two years. The remaining schools are scheduled for similar training during the next year. Many teachers, of course, had taken cooperative learning outside the district in varying amounts; but the on-site district training offered an opportunity to look at certain training variables, namely: (a) training with or without colleagues, (b) training with or without the principal, (c) in-district or out-of-district trainers, and (d) collegial opportunities for skill maintenance.

The initial step was a contact with the staff development office to discuss the feasibility of the study and its potential benefits. A formal letter of request was sent to the school administration. A response of approval and encouragement followed.

After obtaining district approval, the researcher attended one of the regular administrative meetings. This provided an opportunity to meet the nine principals and explain the study in person. Building principals were 
assured that the cumulative findings would be shared with the district and that individual schools would remain anonymous through the use of code numbers for identification. Since the survey was scheduled for early May, a busy time in the calendar, participants were assured of minimal interruptions of school routines in the process of distribution and collection of the data. Each principal was given a copy of the questionnaire to examine; this generated interest in and comfort with the content of the questions. At the end of the presentation, the surveys were collected and questions answered. The support of the school principals was very positive throughout the project. Approval of the survey was granted by the office of Grants and contracts at Portland state University on May 5 , 1989.

\section{DATA COLLECTION}

A packet containing the surveys was delivered to each of the nine elementary school on May 8, 1989. The study, along with the questionnaires, was presented to each school faculty at a staff meeting. The questionnaires were distributed at the staff meeting, except in one school where they were placed in mailboxes.

Each survey had a cover letter which explained that participation was voluntary and anonymous. A business envelope was provided so each response could be sealed when 
it was returned to the collection envelope. Some schools enlisted the help of a teacher who served as a facilitator in getting questionnaires distributed to staff and to absentees. The collection envelope was left in the school office, usually close to the secretarial work area, to provide a neutral and impersonal place for participants to return their sealed responses. The packet was collected from each school after the designated five-day time period. After school was out in June, a follow-up telephone call was made to each principal. The purpose was to provide an opportunity to discuss the climate of the school, special events, and other information which might be relevant to the conduct and results of the study. Procedural details about the administration of the survey in each building were reviewed. A summary of the information obtained from the follow-up calls is presented in Table V. Examination of the procedures for administration of the survey showed consistency necessary for a reliable response. 
TABLE V

DETAILS ON ADMINISTRATION OF THE SURVEY

\begin{tabular}{ll}
\hline School Code and & Details on Administration \\
Number of Respondents & of the Survey
\end{tabular}

School 97: 14 returns out of a possible $18=78 \%$ Principal reported normal Surveys were placed in end-of-year rush. teacher mailboxes; returned to collection envelope in office.

School 87: 15 returns out of a possible $27=56 \%$ Principal reported that the Surveys introduced and staff is accustomed to surveys distributed at a staff in this district. meeting by principal; returned to the collection envelope in the school office.

School 90: 14 returns out of a possible $18=78 \%$ Principal reported this school Surveys were introduced staff was highly involved with cooperative learning methods. and handed out at a staff meeting by the principal; a period of time was given at the meeting to complete the survey along with the option of returning it later to the collection envelope in the school office.

School 57: 5 returns out of a possible $6=83 \%$ Principal reported normal Surveys were introduced end-of-year routine; the school used cooperative learning and houses a video tape file of lessons. by principal at a staff meeting; completed at a later time and returned to the collection envelope.

School 53: 9 returns out of a possible $25=36 \%$ Principal reported that during late April and early May a few Surveys were introduced staff transfers were announced; by the principal at a also several teachers were involved in hiring a new counselor; a nearby business had made a move toward buying staff meeting; completed at a later time and returned to the collection envelope in the school site. in the office. 
TABIE V

DETAILS ON ADMINISTRATION OF THE SURVEY

(continued)

$\begin{array}{ll}\text { School Code and } & \text { Details on Administration } \\ \text { Number of Respondents } & \text { of the Survey }\end{array}$

School 43: 20 returns out of a possible $21=95 \%$

Principal reported busy but normal end-of-year routine; principal personally encouraged staff to respond to the survey.
Surveys were introduced by principal at a staff meeting; time given to complete them with option of returning later to the collection envelope in the secretary's work area.

School 25: 23 returns out of a possible $24=96 \%$ Principal told staff they would Surveys were introduced receive information about the at a staff meeting by the findings of the study; this staff receives cooperative learning training from the principal. principal; time given at the meeting to complete the forms with the option of completing them later; returns made to collection envelope in the school office.

School 41: 13 returns out of a possible $21=62 \%$ Principal reported normal end-of-year routine; heavy schedule of classroom observations at the time of the survey. Surveys were introduced at a staff meeting by the principal; completed at a later time and returned to the collection envelope.

School 48: 16 returns out of a possible $21=76 \%$

Principal reported normal end-of-year routine; said staff members are asked to complete surveys as a matter of routine.

Total number of returns $=129$

Total number distributed $=181$

Rate of return
Surveys were mentioned at a staff meeting by the principal; distributed in mailboxes to be completed and returned to the collection envelope. 


\section{SUMMAPYY OF METHODOLOGY}

When the data were collected, a total of 129 teachers had returned the questionnaire: the number aistributed was 181, making the turn rate $71 \%$. The end-of-year timing gave teachers the opportunity, when answering questions, to think and reflect on the entire year, rather than on singular incidents. The teachers who participated followed the directions extremely well; none of the returned questionnaires had to be discarded because of procedural problems. There were five instances of no response to a survey item and four cases of double answers; these nine cases did not cluster on any particular item. The process had yielded a large collection of the completed surveys ready for analysis. 
CHAPTER IV

\section{RESEARCH FINDINGS}

\section{INTRODUCTION}

This chapter describes the results of the information obtained by the questionnaire and discuss the findings on each of the research questions. The following sections are included: (a) Population Characteristics; (b) Procedure for Analysis; (c) Findings on Questions $1 \mathrm{~A}, 2 \mathrm{~A}$, and $3 \mathrm{~A}$; (d) Findings on questions $2 \mathrm{~A}, 2 \mathrm{~B}$, and $2 \mathrm{C}$; and (e) summary of the Findings.

\section{POPULATION CHARACTERISTICS}

The respondents include 107 females and 22 males. The majority are in the 30's and $40^{\prime} \mathrm{s}$, with 18 in the 50-59 age bracket. A master's degree is held by approximately onethird of the group. Forty-six have taught less than nine years and 56 have taught between 10 and 19 years. The primary level, kindergarten through third grade, is represented by 74 respondents and the intermediate level, fourth through sixth grade, is represented by 41 . Other respondents reported having taught both levels during the past two years. 
The study was conducted in a school district which is active in staff development. In response to the question about how may graduate credits they have earned in the past two years, 41 answered four to six and 63 answered seven or more credits. Active participation in staff development is further evidenced by the fact that $96 \%$ of the respondents report having been trained in ITIP (Instructional Theory Into Practice), 98\% have been trained in Computer Use, $33 \%$ in Peer Coaching, $60 \%$ in Learning Styles, $28 \%$ in Gifted Education, $79 \%$ in Class Management, and $82 \%$ in Cooperative Learning. of the $82 \%$ who report training in cooperative Learning, 43\% fall into the category of 1-10 hours of training and $57 \%$ are in the category of 11-30 training hours. The population sample has, therefore, a substantial number of respondents representing both categories. Respondents who report training in cooperative learning constitute the treatment group; $43 \%$ have received little training while $57 \%$ have received a more substantial amount of training.

PROCEDURE FOR ANALYSIS

The central purpose of the research was to identify a possible significant relationship between training in cooperative learning and level of job satisfaction; overall satisfaction as well as the subsets of efficacy and collegiality. 
A second purpose was to examine how levels of job satisfaction, efficacy, and collegiality vary as a function of the following training variables:

\section{Setting}

2. Amount of use

3. Kind of training

4. Preparation for implementation

5. Opportunity for skill maintenance

After the response packets were collected, the data were converted to numerical values and typed into a computer where the stat view system was used to calculate the statistics. Item 12 in Part I requires explanation. The responses were given a numerical value, as follows:
$A=1$ (0 lessons per week)
$B=2$ (1-3 lessons per week)
$C=3$ (4-6 lessons per week)
$D=4$ (7-9 lessons per week)
$E=5$ (10 or more lessons per week)

Therefore, mean scores are interpreted as follows:

Mean of $1=0$ lessons per week

Mean of $2=1-3$ lessons per week

Mean of $3=4-6$ lessons per week

Mean of $4=7-9$ lessons per week

Mean of $5=10+$ lessons per week

For Part II, the 30-item Job Satisfaction Survey, responses were converted into numerical values as follows: 
$A=5, B=4, C=3, D=2$, and $E=1$. The overall job satisfaction score is based on all 30 test items. The collegiality score is based on 10 items and the efficacy score is based on 15. Table VI lists the subscales and item numbers.

TABLE VI

SUBSCALES OF THE JOB SATISFACTION SURVEY

\begin{tabular}{lll}
\hline Variable & Subscale & Item Numbers* \\
\hline Collegiality & $\begin{array}{l}\text { Peer Support } \\
\text { Collaboration }\end{array}$ & $\begin{array}{l}1,7,13,19,25 \\
2,8,14,20,26\end{array}$ \\
$\begin{array}{l}\text { Power } \\
\text { Confidence } \\
\text { Willingness to } \\
\text { innovate }\end{array}$ & $\begin{array}{l}3,9,15,21,27 \\
\text { General Job } \\
\text { Satisfaction }\end{array}$ & $5,11,17,23,29$ \\
$\begin{array}{c}\text { Overall Job } \\
\text { Satisfaction }\end{array}$ & $6,12,18,24,30$ \\
\hline
\end{tabular}

* Appendix A contains a copy of the survey.

FINDINGS ON QUESTIONS

1A, 1B, AND 1C

Question 1A: Do teachers trained in cooperative learning have a higher level of job satisfaction than teachers who have not had the training?

Null Hypothesis 1A: There will be no difference in overall job satisfaction scores between teachers who 
experience training in cooperative learning and those who do not experience training.

Question 1B: Do teachers trained in cooperative learning have a higher level of collegiality than teachers who have not had the training?

Null Hypothesis 1B: There will be no difference in collegiality scores between teachers who experience training in cooperative learning and those who do not experience training.

Question 1C: Do teachers trained in cooperative learning have a higher level of efficacy than teachers who have not had experienced the training?

Null Hypothesis 1C: There will be no difference in efficacy scores between teachers who experience training in cooperative learning and those who do not experience training.

The independent variable selected for the study was training in cooperative learning. Hypotheses $\mathbf{I A}$, $\mathbf{i B}$, and $1 C$ will be measured by mean scores on the Job Satisfaction Survey •

Items $6 \mathrm{G}$ and 7 gathered information about training. The 106 respondents who answered yes to training had slightly higher mean scores on collegiality, efficacy, and overall job satisfaction than the 23 respondents who reported no training. None of the differences were great enough, however, to be considered significant. Therefore, 
the null hypotheses $1 \mathrm{~A}, 1 \mathrm{~B}$, and $1 \mathrm{C}$ cannot be rejected. This set of hypotheses was measured by mean scores on the Job Satisfaction Survey and the results are displayed in Table VII.

TABLE VII

ITEM 6G: TRAINING IN COOPERATIVE LEARNING

\begin{tabular}{|c|c|c|c|c|c|c|c|}
\hline \multirow[b]{2}{*}{ Group } & \multirow[b]{2}{*}{$\mathbf{n}$} & \multicolumn{2}{|c|}{ Collegiality } & \multicolumn{2}{|c|}{ Efficacy } & \multicolumn{2}{|c|}{$\begin{array}{l}\text { Total Job } \\
\text { Satisfaction }\end{array}$} \\
\hline & & Mean & SD & Mean & $\overline{S D}$ & Mean & \\
\hline $\begin{array}{l}\text { No to } \\
\text { training }\end{array}$ & 23 & 4.187 & .794 & 4.284 & .332 & 4.283 & .434 \\
\hline $\begin{array}{l}\text { Yes to } \\
\text { training }\end{array}$ & 106 & 4.355 & .586 & 4.302 & .275 & 4.353 & .347 \\
\hline
\end{tabular}

There may be several reasons why the means of collegiality, efficacy, and overall job satisfaction did not vary significantly as a function of training in cooperative learning. The means are all notably high, above 4.0, which indicates teachers selected the most positive or second most positive response on most questions. It is apparent that job satisfaction is very high among those who participated in the study, probably due in part to the very active staff development program and also in part to demographic factors. The respondents are elementary classroom teachers; 74 teach primary grades. At the early elementary level, efficacy factors are usually strong and time schedules make collegial 
opportunities frequent. Another contributing factor in the high scores may be the fact that 46 of the respondents are in the first decade of their careers having taught between one to nine years. The very high means for collegiality, efficacy, and total job satisfaction may reflect the general enthusiasm of beginning teachers. In response to question 5, 63 respondents checked $D$, indicating they had earned seven or more graduate level credits over the past two years, which is another sign of the active professional life of the respondents.

Even when the responses to Item 7 were analyzed in terms of number of hours of training, there were no significant differences in means on collegiality, efficacy, and job satisfaction among teachers with varying amounts of training, as shown in Table VIII.

TABLE VIII

ITEM 7 REGROUPED: HOURS OF TRAINING IN COOPERATIVE LEARNING

\begin{tabular}{|c|c|c|c|c|c|c|c|}
\hline \multirow{2}{*}{$\begin{array}{l}\text { Amount of } \\
\text { Training } \\
1-10 \text { hours }\end{array}$} & \multirow[b]{2}{*}{$\mathbf{n}$} & \multicolumn{2}{|c|}{ Collegiality } & \multicolumn{2}{|c|}{ Efficacy } & \multicolumn{2}{|c|}{$\begin{array}{l}\text { Total Job } \\
\text { Satisfaction }\end{array}$} \\
\hline & & Mean & $S D$ & Mean & $\overline{S D}$ & Mean & SD \\
\hline $\begin{array}{l}\text { 1-10 hours } \\
\text { (Little) }\end{array}$ & 33 & 4.367 & .085 & 4.293 & .044 & 4.377 & .3 \\
\hline $\begin{array}{l}\text { 11-20 hours } \\
\text { (Moderate) }\end{array}$ & 39 & 4.398 & .094 & 4.3 & .047 & 4.355 & .35 \\
\hline $\begin{array}{c}\text { 21-30 hours } \\
\text { (High) }\end{array}$ & 34 & 4.287 & .116 & 4.314 & .048 & 4.332 & .392 \\
\hline
\end{tabular}


FINDINGS ON QUESTIONS

$2 A, 2 B$, AND 2C

Question 2A: Is there a relationship between

variables in cooperative learning and level of overall job satisfaction?

Null Hypothesis 2A: There will be no difference in overall job satisfaction scores between teachers who experience different training variables in cooperative learning.

Question 2B: Is there a relationship between variables in cooperative learning training and level of collegiality?

Null Hypothesis 2B: There will be no difference in collegiality scores between teachers who experience different training variables in cooperative learning.

Question 2C: Is there a relationship between variables in cooperative learning training and level of efficacy?

Null Hypothesis 2C: There will be no difference in efficacy scores between teachers who experience different training variables in cooperative learning.

A second purpose of the study was to examine how levels of collegiality, efficacy, and overall job satisfaction vary as a function of the following training variables: (a) setting, (b) amount of use, (c) kind of training, (d) preparation for implementation, and (e) 
opportunities for skill maintenance. The data on training variables were gathered from the 106 respondents who reported having been trained in cooperative learning.

Training Variable \#1:

setting

The training variable of setting is based on the literature which supports the opinion that site-based change efforts and school-embedded training have an advantage over innovations and staff development from the outside (David, 1989). Items 9, 10, and 11 asked if training was with or without school colleagues, with or without the principal, and with in-district or out-of-district trainers. The results show none of these factors has a significant impact on job satisfaction, collegiality, or efficacy; a finding which runs counter to the literature.

Once again the findings may have been influenced by the population sample. The teachers who participated report very active participation in a broad variety of staff development; 99\% report taking graduate level courses over the past two years. It is highly probable they have taken some of their classes with colleagues, with the principal, and with in-district trainers. Consequently, it is difficult to isolate the impact of the cooperative learning training on teachers. 
Training Variable \#2:

Amount of Use

Item 12 gathered data on the number of lessons per week in which the teacher used cooperative learning. Those who report using it seven or more items per week also report significantly higher efficacy. This finding rejects the null hypothesis, 2c. Efficacy means were higher where there was greater use of cooperative learning. Higher efficacy among teachers means greater sense of power, confidence, and willingness to innovate. Table IX presents the findings.

TABLE IX

ITEM 12: AMOUNT OF USE (COLLAPSED TO THREE LEVELS)

\begin{tabular}{|c|c|c|c|c|c|c|c|}
\hline \multirow{2}{*}{$\begin{array}{l}\text { Lessons } \\
\text { Per Week }\end{array}$} & \multirow[b]{2}{*}{$\mathbf{n}$} & \multicolumn{2}{|c|}{ Collegiality } & \multicolumn{2}{|c|}{ Efficacy } & \multicolumn{2}{|c|}{$\begin{array}{l}\text { Total Job } \\
\text { Satisfaction }\end{array}$} \\
\hline & & Mean & SD & Mean & SD & Mean & SD \\
\hline (1) $0-3$ & 54 & 4.373 & .599 & 4.242 & .245 & 4.32 & .337 \\
\hline (2) $4-6$ & 31 & 4.33 & .48 & 4.28 & .268 & 4.343 & .315 \\
\hline (3) $7+$ & 20 & 4.34 & .729 & $4.497 *$ & .264 & 4.45 & .42 \\
\hline
\end{tabular}

An analysis of variance, using amount of use as the independent variable and the efficacy score as the dependent variable was performed. The statistical hypothesis that there would be no significant difference between the efficacy means of the three levels of use (H:M $\left.=M_{2}=M_{3}\right)$ 
was rejected $(p<.01))$. Table $X$ provides the analysis of variance.

TABLE X

ANOVA FOR AMOUNT OF USE AND EFFICACY

\begin{tabular}{|c|c|c|c|c|c|}
\hline Variable & $\begin{array}{l}\text { Source of } \\
\text { Variation }\end{array}$ & $\begin{array}{l}\text { Sum of } \\
\text { Squares }\end{array}$ & DF & $\begin{array}{l}\text { Mean } \\
\text { Square }\end{array}$ & $F$ \\
\hline Amount of use & $\begin{array}{l}\text { Between } \\
\text { Within } \\
\text { Total }\end{array}$ & $\begin{array}{r}.967 \\
6.955 \\
7.922\end{array}$ & $\begin{array}{r}2 \\
102 \\
104\end{array}$ & $\begin{array}{l}.484 \\
.068\end{array}$ & $7.094 *$ \\
\hline
\end{tabular}

$\approx p<.01$

Further analysis using the scheffé test was conducted to see which pairs of the meäns differed significantly at alpha $=.05$. The following pairs of efficacy means were tested: $\overline{\mathrm{X}}_{1}-\overline{\mathrm{X}}_{2} ; \overline{\mathrm{X}}_{1}-\overline{\mathrm{X}}_{3} ;$ and $\overline{\mathrm{X}}_{2}-\overline{\mathrm{X}}_{3}$. A significant difference was found between $\bar{x}_{1}-\bar{x}_{3}$ and $\bar{x}_{2}-\bar{x}_{3}$, as presented in Table XI.

TABLE XI

SCHEFFÉ F-TEST FOR AMOUNT OF USE AND EFFICACY

\begin{tabular}{lll}
\hline Group & \multicolumn{2}{c}{ Comparison of } \\
Lessons Per Week & $\begin{array}{l}\text { Scheffé } \\
\text { F-test }\end{array}$ \\
\hline$\overline{\mathrm{X}}_{1}-\overline{\mathrm{x}}_{2}$ & $0-3$ vs $4-6$ & .215 \\
$\overline{\mathrm{x}}_{1}-\overline{\mathrm{x}}_{3}$ & $0-3$ vs $7+$ & $6.947 *$ \\
$\overline{\mathrm{x}}_{2}-\overline{\mathrm{X}}_{3}$ & $4-6$ vs $7+$ & $4.166 *$ \\
\hline$\overline{\text { Significant at } .05}$ level
\end{tabular}


Training Variable \#3:

Kind of Training

Item 13 gathered information about the class or workshop in which cooperative learning was presented to teachers. Five components of training were investigated:

1. Background theory

2. Modeling of methods

3. Small group sharing and problem solving

4. Practice activities during class

5. Feedback after early application

The findings, as presented in Table XII, show no significant relationship between the number of yes answers and level of collegiality, efficacy, or job satisfaction. This holds true even for respondents who answered yes to all five components of training.

TABLE XII

13A-E: KIND OF TRAINING (AVERAGE COLLAPSED)

\begin{tabular}{|c|c|c|c|c|c|c|c|}
\hline \multirow{2}{*}{$\begin{array}{l}\text { Kind of } \\
\text { Training }\end{array}$} & \multirow[b]{2}{*}{$\mathbf{n}$} & \multicolumn{2}{|c|}{ Collegiality } & \multicolumn{2}{|c|}{ Efficacy } & \multicolumn{2}{|c|}{$\begin{array}{l}\text { Total Job } \\
\text { Satisfaction }\end{array}$} \\
\hline & & Mean & SD & Mean & SD & Mean & SD \\
\hline \multicolumn{8}{|l|}{ Yes to 3} \\
\hline or fewer & 6 & 4.017 & .842 & 4.133 & .283 & 4.128 & .525 \\
\hline Yes to 4 & 19 & 4.247 & .64 & 4.261 & .259 & 4.298 & .36 \\
\hline \multicolumn{8}{|l|}{ Yes to } \\
\hline al1 5 & 81 & 4.406 & .548 & 4.325 & .275 & 4.383 & .326 \\
\hline
\end{tabular}


While the total number of yes answers from individual respondents was not significant, a yes answer to one particular training component was important. Where there was group sharing and problem solving, item 13C, teachers had both higher efficacy and job satisfaction. These results, although based on a very small number of respondents in the "no" category, point to group sharing and problem solving as a powerful training component. Table XIII presents the results.

TABLE XIII

ITEM 13C: GROUP SHARING

\begin{tabular}{|c|c|c|c|c|c|c|c|}
\hline \multirow{2}{*}{$\begin{array}{l}\text { Group } \\
\text { Sharing } \\
\text { No }\end{array}$} & \multirow{2}{*}{$\begin{array}{r}\text { n } \\
4\end{array}$} & \multicolumn{2}{|c|}{$\begin{array}{l}\text { Collegiality } \\
\text { Mean SD }\end{array}$} & \multicolumn{2}{|c|}{$\begin{array}{l}\text { Efficacy } \\
\text { Mean SD }\end{array}$} & \multicolumn{2}{|c|}{$\begin{array}{l}\text { Total Job } \\
\text { Satisfaction } \\
\text { Mean SD }\end{array}$} \\
\hline & & 3.825 & 1.014 & 4.033 & .301 & 3.992 & .618 \\
\hline Yes & 102 & 4.376 & .561 & $4.313 *$ & .27 & $4.367 *$ & .329 \\
\hline
\end{tabular}

An analysis of variance, using group sharing as the independent variable and the efficacy score as the dependent variable was performed; alpha was set at .05. The statistical hypothesis that there would be no significant aifference between the efficacy means of the swo groups $\left(\mathrm{H}: \mathrm{M}_{1}=\mathrm{M}_{2}\right)$ was rejected $(\mathrm{p}<.05)$. Table XIV provides the analysis of variance. 
TABLE XIV

ANOVA FOR 13C: GROUP SHARING

AND EFFICACY

\begin{tabular}{lllrll}
\hline Variable & $\begin{array}{l}\text { Source of } \\
\text { Variation }\end{array}$ & $\begin{array}{l}\text { Sum of } \\
\text { Squares }\end{array}$ & DF & $\begin{array}{l}\text { Mean } \\
\text { Square }\end{array}$ & F \\
\hline Group Sharing & $\begin{array}{l}\text { Between } \\
\text { Within }\end{array}$ & 7.624 & 104 & $\begin{array}{r}1 \\
.073\end{array}$ & $4.103 *$ \\
& Total & 7.925 & 105 & & \\
\hline
\end{tabular}

* $p<.05$

An analysis of variance, using group sharing as the independent variable and the total job satisfaction score as the dependent variable was performed; alpha was set at .05 . The statistical hypothesis that there would be no significant difference between the job satisfaction means of the two groups $\left(\mathrm{H}: \mathrm{M}_{1}=\mathrm{M}_{2}\right)$ was rejected $(\mathrm{p}<.05)$. Table XV provides the analysis of variance.

TABLE XV

ANOVA FOR 13C: GROUP SHARING AND JOB SATISFACTION

\begin{tabular}{lllrll}
\hline Variable & $\begin{array}{l}\text { Source of } \\
\text { Variation }\end{array}$ & $\begin{array}{l}\text { Sum of } \\
\text { Squares }\end{array}$ & DF & $\begin{array}{l}\text { Mean } \\
\text { Square }\end{array}$ & F \\
\hline Group Sharing & $\begin{array}{l}\text { Between } \\
\text { Within } \\
\text { Total }\end{array}$ & 12.089 & 104 & .116 & $4.675 *$ \\
& 12.632 & 105 & & \\
\hline $\mathrm{p}<.05$ & & & & &
\end{tabular}


Training Variable \#3:

Kind of Training Compared

with Training Variable \#2:

Amount of Use

When the responses to item 13 are compared with those of item 12, the findings are significant. There is greater use of cooperative learning by teachers who responded yes to four or five of the training questions as opposed to yes to three or fewer questions. Table XVI presents the means for each group.

TABLE XVI

I3A-E: KIND OF TRAINING (COLLAPSED)

AND USE PER WEEK

Kind of

Training

n

Use Per Weeke

Mean

SD

(1) 3 or fewer

6

2.167

.408

(2) 4 components

19

$2.421 *$

.961

(3) 5 components

80

2.888 *

.994

* $\mathrm{p}<.05$

eMean of $1=0$ lessons per week
Mean of $2=1-3$ lessons per week
Mean of $3=4-6$ lessons per week
Mean of $4=7-9$ lessons per week
Mean of $5=10+$ lessons per week

An analysis of variance, using use per week as the dependent variable and kind of training as the independent variable was performed with alpha set at .05. Further analysis, using ANOVA was conducted to see which pairs of means differed significantly at alpha $=.05$. The following 
means on use per week were tested: $\bar{x}_{1}-\bar{x}_{2} ; \bar{x}_{1}-\bar{x}_{3} ;$ and $\bar{X}_{2}-\bar{X}_{3}$. A significant difference was found between $\bar{x}_{1}-\bar{X}_{3}$ and between $\bar{x}_{2}-\bar{x}_{3}$. Table XVII presents an analysis of variance between the use per week of cooperative learning and kind of training.

TABLE XVII

ANOVA FOR 13A-E: KIND OF TRAINING AND USE PER WEEK

\begin{tabular}{|c|c|c|c|c|c|}
\hline Variable & $\begin{array}{l}\text { Source of } \\
\text { Variation }\end{array}$ & $\begin{array}{l}\text { Sum of } \\
\text { squares }\end{array}$ & DF & $\begin{array}{l}\text { Mean } \\
\text { Square }\end{array}$ & $\mathbf{F}$ \\
\hline \multirow[t]{2}{*}{ Kind of Training } & $\begin{array}{l}\text { Between } \\
\text { within }\end{array}$ & $\begin{array}{r}5.595 \\
95.452\end{array}$ & $\begin{array}{r}2 \\
102\end{array}$ & $\begin{array}{r}2.798 \\
.936\end{array}$ & $2.99 *$ \\
\hline & Total & 101.048 & 104 & & \\
\hline
\end{tabular}

Three of the training components in item 13 are collegial in nature: small group sharing (Part C), cooperative activities (Part D), and feedback from an observer (Part E). The significant comparison between the two training variables, Kind of Training and Amount of Use, supports the literature which advocates collaborative activities during training. Staff inservice presents an opportunity to reduce teacher isolation and provide a setting where colleagues can share problems, get help, and give testimonials about successes. Collegial activities are 
found here to be associated with frequent application of the new method.

Feedback from a oualified Observer: $13 \mathrm{E}$ and Training

Variable \#2: Amount of Use

Item $13 \mathrm{E}$ asked teachers if they received feedback from a qualified observer as they tried the new techniques in their own classroom. The comparison between the "feedback" question (13E) and amount of use was significant as shown in Table XVIII which presents the means for each group of respondents, those who did not receive feedback and those who did.

TABLE XVIII

\section{E: FEEDBACK AND 12: AMOUNT OF USE (COLLAPSED)}

\begin{tabular}{lccc}
\hline Group & $\mathrm{n}$ & Meane & SD \\
\hline No to feedback & 20 & 1.3 & .647 \\
Yes to feedback & 85 & $1.765 *$ & .085 \\
\hline * $<.05$ & $\begin{array}{l}\text { EAmount of Use Collapsed to } 3 \text { levels } \\
\text { Mean of } 1=0-3 \text { lessons per week } \\
\text { Mean of } 2=4-6 \text { lessons per week } \\
\text { Mean of } 3=7+\text { lessons per week }\end{array}$ \\
An analysis of variance, using amount of use as the \\
was performed; alpha was set at . 05. The results are \\
presented in Table XIX.
\end{tabular}


TABLE XIX

ANOVA FOR 13E: FEEDBACK AND 12: AMOUNT OF USE (COLLAPSED)

\begin{tabular}{|c|c|c|c|c|c|}
\hline Variable & $\begin{array}{l}\text { Source of } \\
\text { Variation }\end{array}$ & $\begin{array}{l}\text { Sum of } \\
\text { Squares }\end{array}$ & DF & $\begin{array}{l}\text { Mean } \\
\text { Square }\end{array}$ & $\mathbf{F}$ \\
\hline \multirow[t]{2}{*}{ Feedback } & $\begin{array}{l}\text { Between } \\
\text { within }\end{array}$ & $\begin{array}{r}3.496 \\
59.494\end{array}$ & $\begin{array}{r}1 \\
103\end{array}$ & $\begin{array}{r}3.496 \\
.578\end{array}$ & $6.053 *$ \\
\hline & Total & 62.99 & 104 & & \\
\hline
\end{tabular}

Early implementation of new methods may be awkward and in need of refinement. without feedback--which should include encouragement for the teacher during this stage-innovations may be infrequently used or soon forgotten. The finding that feedback during early implementation is associated with greater amount of use is especially important because of the previous finding which associates use with higher teacher efficacy.

\section{Training Variable \#4:}

\section{Preparation for Implementation}

Item 14 asked teachers how well their training prepared them to implement cooperative learning in the classroom. Quality of preparation did not show a significant relationship to collegiality, efficacy, or job satisfaction. Satisfaction levels of those who participated in the study are high in general; probably the quality of 
the preparation for implementation of cooperative learning is not sufficiently isolated by the questionnaire as a separate and distinct factor in level of satisfaction. The population sample has experienced a variety of training topics, many of which are related to levels of collegiality, efficacy, and satisfaction.

Training Variable \#4: Preparation for Implementation Compared with Training Variable \#2: Amount of Use

When responses to item 14, quality of preparation for implementation, are compared to item 12, amount of use, the results are significant. Those who report being extremely well prepared for implementation also report greater use of cooperative learning per week. These findings support the need teachers have for practical and realistic training which can be applied in the real setting of the classroom. The absence of this training variable may result in low levels of implementation, as shown in Table XX in which the means for each group are presented.

Table XXI presents the analysis of variance for quality of preparation for implementation and amount of use. Further analysis using the Fisher test was conaucted to see which pairs of means differed significantly at alpha $=.05$. A significant difference was found between $\bar{x}_{1}-\bar{x}_{3}$ and $\bar{X}_{1}-\bar{X}_{4}$ as presented in Table XXII. 
TABLE XX

ITEM 14: PREPARATION FOR IMPLEMENTATION AND USE PER WEEK

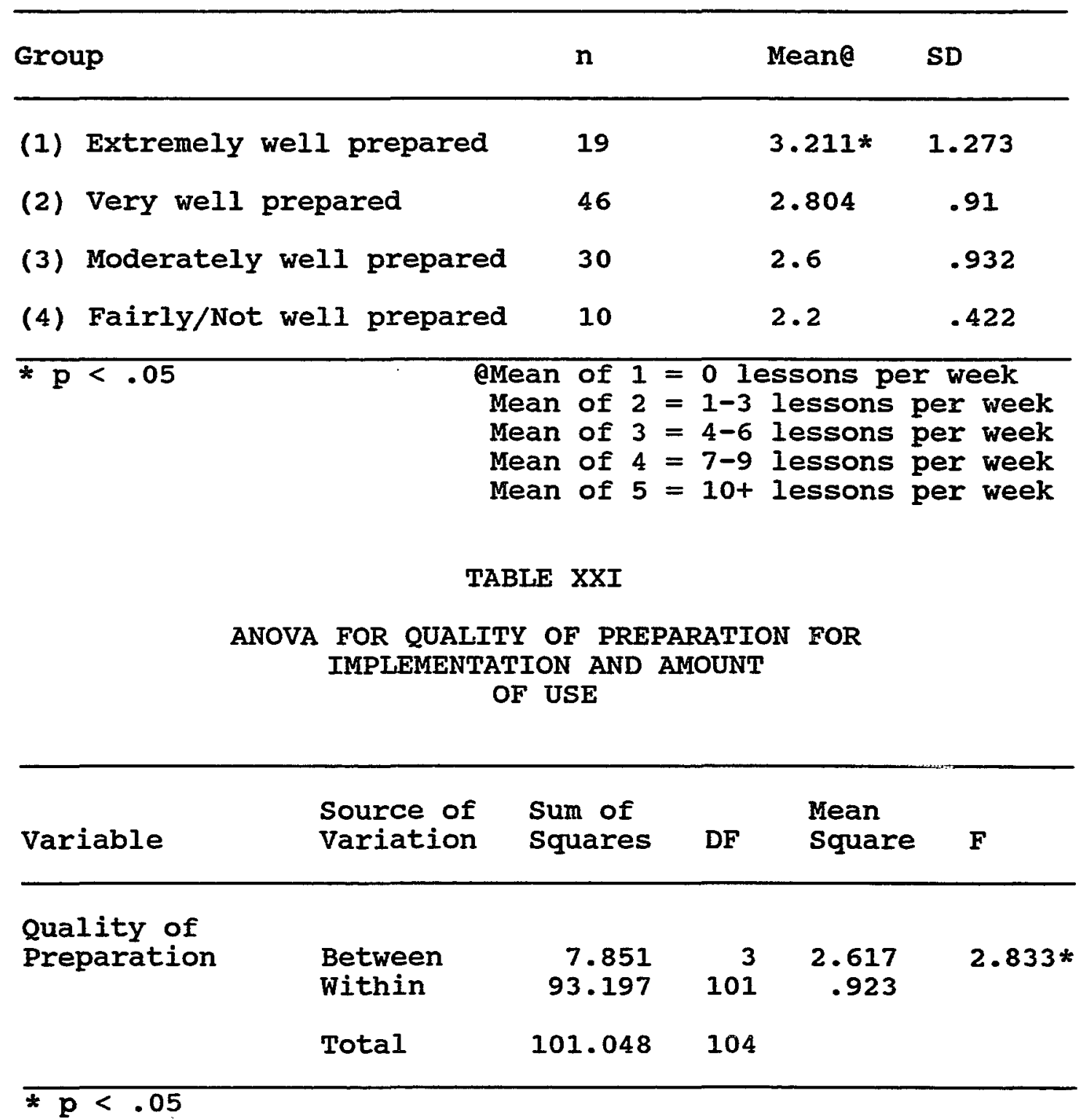


TABLE XXII

FISHER TEST FOR QUALITY OF PREPARATION FOR IMPLEMENTATION AND AMOUNT OF USE

\begin{tabular}{lll}
\hline Group & Comparison & Fisher \\
\hline$\overline{\mathrm{X}}_{1}-\overline{\mathrm{X}}_{2}$ & Extremely vs Very & .52 \\
$\overline{\mathrm{X}}_{1}-\overline{\mathrm{X}}_{3}$ & Extremely vs Moderately & $.559 *$ \\
$\overline{\mathrm{x}}_{1}-\overline{\mathrm{X}}_{4}$ & Extremely vs Fairly/Not & $.745 *$ \\
$\overline{\mathrm{X}}_{2}-\overline{\mathrm{X}}_{3}$ & Very vs Moderately & .447 \\
$\overline{\mathrm{X}}_{2}-\overline{\mathrm{X}}_{4}$ & Very vs Fairly/Not & .665 \\
$\bar{x}^{*}$ Significant at .05 level
\end{tabular}

Figure 1 presents a graph of the data from Table XX.

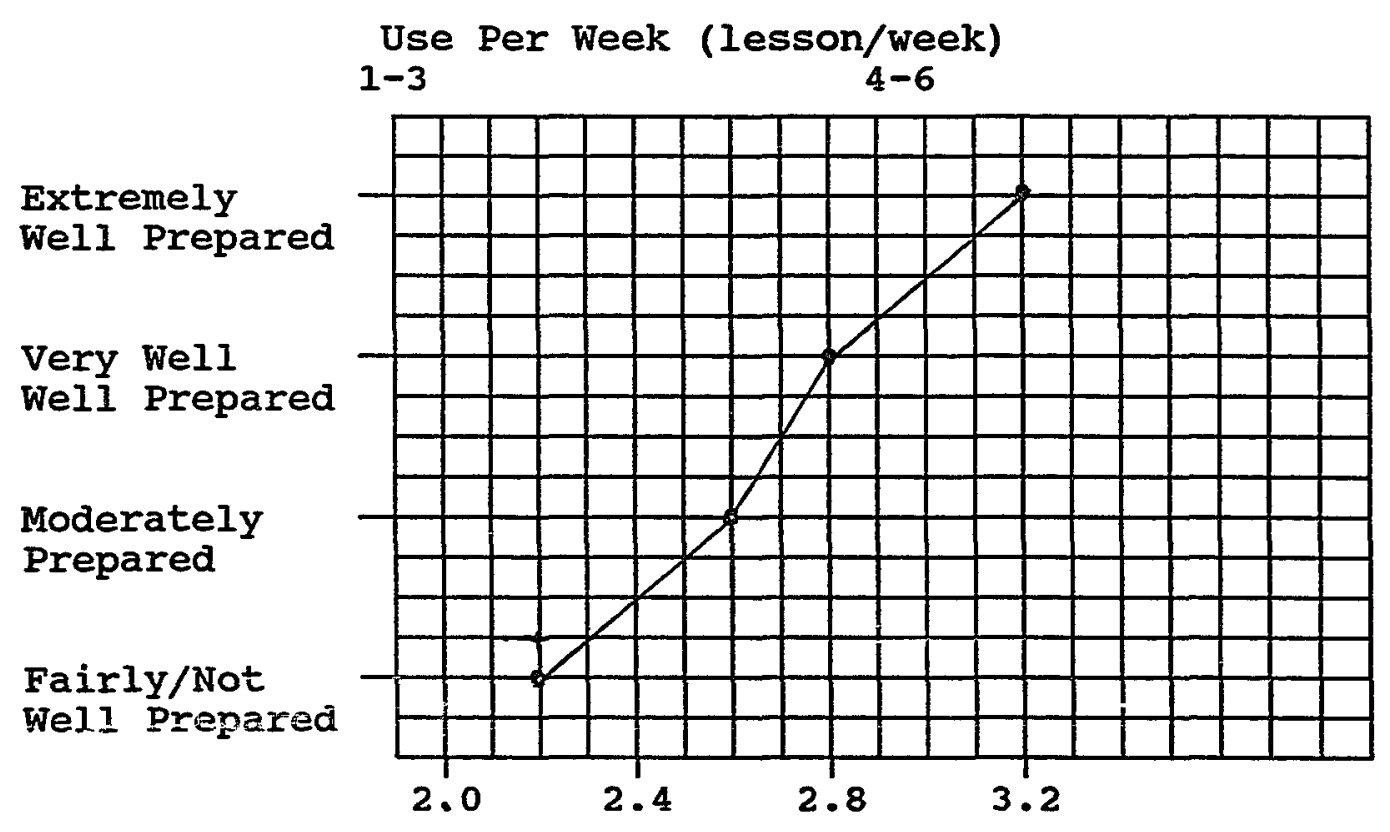

Figure 1. Graph showing preparation for implementation and use of cooperative learning per week. 
Training Variable \#5:

Opportunities for Skill

Maintenance

Item 15 gathered information about teachers'

opportunities to maintain skills in cooperative learning. Five opportunities were examined:

1. Discussion with colleagues

2. Peer coaching and feedback

3. Staff meeting discussion

4. Principal observation and feedback

5. Assistance from staff development personnel

Each of the skill maintenance opportunities requires interaction between two or more colleagues; none can be accomplished in isolation. The findings show that both collegiality and job satisfaction are significantly higher when teachers use five opportunities to maintain skills than when four or fewer opportunities are used. Table XXIII presents the findings.

TABLE XXIII

OPPORTUNITIES FOR SKILL MAINTENANCE (COLLAPSED)

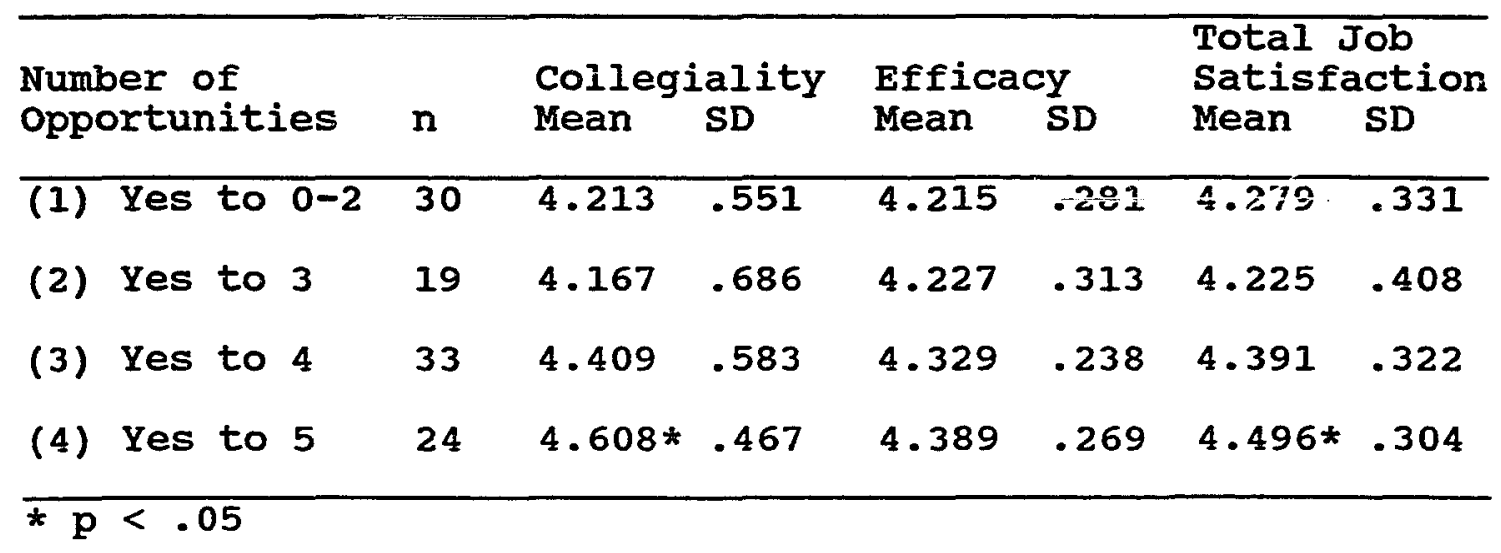


An analysis of variance, using number of opportunities for skill maintenance as the independent variable and scores on collegiality and total job satisfaction as dependent variables was performed; alpha was set at .05. The statistical hypothesis that there would be no significant difference between the collegiality means and the total job satisfaction means of the four groups who experienced different numbers of skill maintenance opportunities was rejected $\left(\mathrm{H}: \mathrm{M}_{1}=\mathrm{M}_{2}=\mathrm{M}_{3}=\mathrm{M}_{4},(\mathrm{p}<.05) ;\right.$ Table XXIV presents the analysis of variance for the number of opportunities for skill maintenance and collegiality.

TABLE XXIV

ANOVA FOR NUMBER OF OPPORTUNITIES FOR SKILL MAINTENANCE AND COLLEGIALITY

\begin{tabular}{lllrll}
\hline Variable & $\begin{array}{l}\text { Source of } \\
\text { Variation }\end{array}$ & $\begin{array}{l}\text { Sum of } \\
\text { Squares }\end{array}$ & DF & $\begin{array}{l}\text { Mean } \\
\text { Square }\end{array}$ & F \\
\hline $\begin{array}{llllll}\text { Number of skill } \\
\text { maintenance } \\
\text { opportunities }\end{array}$ & $\begin{array}{l}\text { Between } \\
\text { Within }\end{array}$ & 33.158 & 102 & .325 & $2.982 *$ \\
& Total & 36.065 & 105 & & \\
\hline T & & & & &
\end{tabular}

Table XXV presents the analysis of variance for the relationship between number of opportunities for skill maintenance and total job satisfaction. 
TABLE XXV

ANOVA FOR NUMBER OF OPPORTUNITIES FOR SKILL MAINTENANCE AND OVERALL JOB

SATISFACTION

\begin{tabular}{lllrlll}
\hline Variable & $\begin{array}{l}\text { Source of } \\
\text { Variation }\end{array}$ & $\begin{array}{l}\text { Sum of } \\
\text { squares }\end{array}$ & DF & $\begin{array}{l}\text { Mean } \\
\text { Square }\end{array}$ & F \\
\hline $\begin{array}{l}\text { Number of skill } \\
\text { maintenance } \\
\text { opportunities }\end{array}$ & $\begin{array}{l}\text { Between } \\
\text { Within }\end{array}$ & 11.618 & 102 & .114 & $2.968 *$ \\
& Total & 12.632 & 105 & & \\
& & & & & \\
& & & & & & \\
\end{tabular}

$\star p<.05$

Further analysis, using the Fisher test, was conducted to see which pairs of means differed significantly at the .05 level. The following pairs of collegiality means were tested: $\quad \overline{\mathrm{X}}_{1}-\overline{\mathrm{X}}_{2} ; \overline{\mathrm{X}}_{1}-\overline{\mathrm{X}}_{3} ; \overline{\mathrm{X}}_{1}-\overline{\mathrm{X}}_{4} ; \overline{\mathrm{X}}_{2}-\overline{\mathrm{X}}_{3} ;$ and $\overline{\mathrm{X}}_{2}-\overline{\mathrm{X}}_{4} \cdot \mathrm{A}$ significant difference was found between $\bar{X}_{1}-\bar{X}_{4}$ and $\bar{X}_{2}-\bar{X}_{4}$, as presented in Table XXVI.

The Fisher test was also conducted to see which pairs of means on overall job satisfaction differed significantly. The following pairs of means were tested: $\bar{x}_{1}-\bar{x}_{2} ; \bar{x}_{1}-\bar{x}_{3}$; $\overline{\mathrm{X}}_{1}-\overline{\mathrm{X}}_{4} ; \overline{\mathrm{X}}_{2}-\overline{\mathrm{X}}_{4} ;$ and $\overline{\mathrm{X}}_{3}-\overline{\mathrm{X}}_{4}$. A significant difference was found between $\bar{x}_{1}-\bar{x}_{4}$ and $\bar{x}_{2}-\bar{x}_{4}$, as presented in Table XXVII. 
TABLE XXVI

FISHER TEST FOR NUMBER OF SKILL MAINTENANCE OPPORTUNITIES AND COLLEGIALITY

\begin{tabular}{lll}
\hline Group & Comparison & Fisher \\
\hline$\overline{\mathrm{X}}_{1}-\overline{\mathrm{X}}_{2}$ & Yes to 2 or fewer vs Yes to 3 & .332 \\
$\overline{\mathrm{X}}_{1}-\overline{\mathrm{X}}_{3}$ & Yes to 2 or fewer vs Yes to 4 & .285 \\
$\overline{\mathrm{X}}_{1}-\overline{\mathrm{X}}_{4}$ & Yes to 2 or fewer vs Yes to 5 & $.31 *$ \\
$\overline{\mathrm{X}}_{2}-\overline{\mathrm{X}}_{3}$ & Yes to 3 vs Yes to 4 & .326 \\
$\overline{\mathrm{X}}_{2}-\overline{\mathrm{X}}_{4}$ & Yes to 3 vs Yes to 5 & $.347 *$ \\
\hline * Significant at .05 level
\end{tabular}

TABLE XXVII

FISHER TEST FOR NUMBER OF SKIIL MAINTENANCE OPPORTUNITIES AND OVERALI JOB

SATISFACTION

\begin{tabular}{lll}
\hline Group & Comparison & Fisher \\
\hline$\overline{\mathrm{X}}_{1}-\overline{\mathrm{X}}_{2}$ & Yes to 2 or fewer vs Yes to 3 & .196 \\
$\overline{\mathrm{X}}_{1}-\overline{\mathrm{X}}_{3}$ & Yes to 2 or fewer vs Yes to 4 & .169 \\
$\overline{\mathrm{x}}_{1}-\overline{\mathrm{x}}_{4}$ & Yes to 2 or fewer vs Yes to 5 & $.183 *$ \\
$\overline{\mathrm{X}}_{2}-\overline{\mathrm{X}}_{3}$ & Yes to 3 vs Yes to 4 & .193 \\
$\overline{\mathrm{X}}_{2}-\overline{\mathrm{X}}_{4}$ & Yes to 3 vs Yes to 5 & $.206 *$ \\
$\bar{x}_{\text {Significant at } .05 \text { level }}$ &
\end{tabular}

Item 15 was also analyzed in terms of each item and its relationship to collegiality, efficacy, and total job 
satisfaction. A total of four significant comparisons were found; each will be presented in separate tables on subsequent pages. Table XXVIII presents a summary of the findings.

The results show peer coaching associated with both collegiality and job satisfaction; a finding which supports the recommendations of Joyce and Showers (1988). Discussion with colleagues and principal observation and feedback are both associated with efficacy; a finding which supports the recommendations of Fullan (1982), Rosenholtz (1989), and Sparks (1988) .

TABLE XXVIII

SUMMARY OF SIGNIFICANT COMPARISONS BETWEEN SKILL MAINTENANCE OPPORTUNITIES AND LEVELS OF

COLIEGIALITY, EFFICACY, AND JOB SATISFACTION

Opportunity for skill Maintenance
Collegiality Efficacy Satisfaction

A. Discussion with colleagues

B. Peer coaching and feedback

c. Staff meeting discussions

D. Principal observation and feedback

E. Assistance from staff development personnel

No

Yes*

No

No

No
Yes*

No

No

Yes*

No
No

Yes*

No

No

No

* Significant at .05 level 
An analysis of variance, using discussion with colleagues as the independeni variable and the efficacy score as the dependent variable was performed; alpha was set at .05. The statistical hypothesis that there would be no significant difference between the efficacy means of the two groups $\left(\mathrm{H}: \mathrm{M}_{1}=\mathrm{M}_{2}\right)$ was rejected $(\mathrm{p}<.05)$. Table XXIX presents the mean scores for each group.

TABLE XXIX

ITEM 15A: DISCUSS WITH COLIEAGUES AND EFFICACY

\begin{tabular}{llll}
\hline Group & $\mathrm{n}$ & Mean & SD \\
\hline No & 12 & 4.089 & .2 \\
Yes & 94 & 4.33 & .272 \\
\hline
\end{tabular}

Table XXX presents the analysis of variance between discussion with colleagues and efficacy.

TABLE XXX

ANOVA FOR 15A: DISCUSSION WITH COLLEAGUES AND EFFICACY

\begin{tabular}{|c|c|c|c|c|c|}
\hline Variable & $\begin{array}{l}\text { Source of } \\
\text { Variation }\end{array}$ & $\begin{array}{l}\text { Sum of } \\
\text { Squares }\end{array}$ & DF & $\begin{array}{l}\text { Mean } \\
\text { Square }\end{array}$ & $\mathbf{F}$ \\
\hline \multirow[t]{2}{*}{$\begin{array}{l}\text { Discussion with } \\
\text { colleagues }\end{array}$} & $\begin{array}{l}\text { Between } \\
\text { Within }\end{array}$ & $\begin{array}{r}.617 \\
7.309\end{array}$ & $\begin{array}{r}1 \\
104\end{array}$ & $\begin{array}{l}.617 \\
.07\end{array}$ & $8.773 *$ \\
\hline & Total & 7.925 & 105 & & \\
\hline
\end{tabular}


An analysis of variance, using peer coaching as the independent variable and the collegiality scores as the dependent variable was performed; alpha was set at .05 . The statistical hypothesis that there would be no significant difference between the collegiality means of the two groups $\left(H: M_{1}=M_{2}\right)$ was rejected $(p<.05)$. Table XXXI presents the mean scores for each group.

TABLE XXXI

ITEM 15B: PEER COACHING AND COLLEGIALITY

\begin{tabular}{llll}
\hline Group & $\mathrm{n}$ & Mean & SD \\
\hline No & 69 & 4.235 & .624 \\
Yes & 37 & 4.579 & .432 \\
\hline
\end{tabular}

Table XXXII presents the analysis of variance between peer coaching and collegiaíty.

TABLE XXXII

ANOVA FOR 15B: PEER COACHING

AND COLLEGIALITY

\begin{tabular}{|c|c|c|c|c|c|}
\hline Variable & $\begin{array}{l}\text { Source of } \\
\text { Variation }\end{array}$ & $\begin{array}{l}\text { Sum of } \\
\text { Squares }\end{array}$ & DF & $\begin{array}{l}\text { Mean } \\
\text { Square }\end{array}$ & $\mathbf{F}$ \\
\hline \multirow[t]{2}{*}{ Peer coaching } & $\begin{array}{l}\text { Between } \\
\text { within }\end{array}$ & $\begin{array}{r}2.852 \\
33.213\end{array}$ & $\begin{array}{r}1 \\
104\end{array}$ & $\begin{array}{r}2.852 \\
.319\end{array}$ & $8.932 *$ \\
\hline & Total & 36.065 & 105 & & \\
\hline
\end{tabular}


An analysis of variance, using peer coaching as the independent variable and the job satisfaction score as the dependent variable was performed; alpha was set at .05 . The statistical hypothesis that there would be no significant difference between the job satisfaction means of the two groups $\left(\mathrm{H}: \mathrm{M}_{1}=\mathrm{M}_{2}\right)$ was rejected $(\mathrm{p}<.05)$. Table XXXIII presents the mean scores for each group.

TABLE XXXIII

ITEM 15B: PEER COACHING AND JOB SATISFACTION

\begin{tabular}{llll}
\hline Group & $\mathrm{n}$ & Mean & $\mathrm{SD}$ \\
\hline No & 69 & 4.285 & .368 \\
Yes & 37 & 4.48 & .264 \\
\hline
\end{tabular}

Table XXXIV present the analysis of variance between per coaching and job satisfaction.

TABLE XXXIV

ANOVA FOR 15B: PEER COACHING AND JOB SATISFACTION

\begin{tabular}{llrrrr}
\hline Variable & $\begin{array}{l}\text { Source of } \\
\text { Variation }\end{array}$ & $\begin{array}{l}\text { Sum of } \\
\text { Squares }\end{array}$ & DF & $\begin{array}{l}\text { Mean } \\
\text { Square }\end{array}$ & F \\
\hline Peer coaching & $\begin{array}{l}\text { Between } \\
\text { Within }\end{array}$ & 11.723 & 104 & .909 & $8.061 *$ \\
& Total & 12.632 & 105 & & \\
\hline * $\mathrm{p}<.05$ & & & & &
\end{tabular}


An analysis of variance, using principal observation and feedback as the independent variable and the efficacy score as the dependent variable was performed; alpha was set at .05. The statistical hypothesis that there would be no significant difference between the job satisfaction means of the two groups $\left(\mathrm{H}: \mathrm{M}_{1}=\mathrm{M}_{2}\right)$ was rejected $(\mathrm{p}<.05)$. Table XXXV presents the mean scores for each group.

TABLE XXXV

ITEM 15D: PRINCIPAL OBSERVATION/FEEDBACK AND EFFICACY

\begin{tabular}{llll}
\hline Group & $\mathrm{n}$ & Mean & SD \\
\hline No & 27 & 4.208 & .335 \\
Yes & 79 & 4.334 & .245 \\
\hline
\end{tabular}

Table XXXVI presents analysis of variance between principal observation and feedback and efficacy.

TABLE XXXVI

ANOVA FOR 15D: PRINCIPAL OBSERVATION/ FEEDBACK AND EFFICACY

\begin{tabular}{lllrll}
\hline Variable & $\begin{array}{l}\text { Source of } \\
\text { Variation }\end{array}$ & $\begin{array}{l}\text { Sum of } \\
\text { Squares }\end{array}$ & DF & $\begin{array}{l}\text { Mean } \\
\text { Square }\end{array}$ & F \\
\hline $\begin{array}{l}\text { Principal } \\
\text { observation/ } \\
\text { feedback }\end{array}$ & $\begin{array}{l}\text { Between } \\
\text { Within }\end{array}$ & 7.606 & 104 & .319 & $4.365 *$ \\
& Total & 7.925 & 105 & & \\
& & & & & \\
& & & & &
\end{tabular}


Training Variable \#5:

Opportunities for skill

Maintenance compared with

Training Variable \#2:

Amount of Use

The use of four or five of the opportunities for skill maintenance as opposed to two or fewer shows a significant relationship to greater use of cooperative learning in the classroom. Table XXXVII presents group means on use per week.

TABLE XXXVII

OPPORTUNITIES FOR SKILI MAINTENANCE

AND USE PER WEEK@

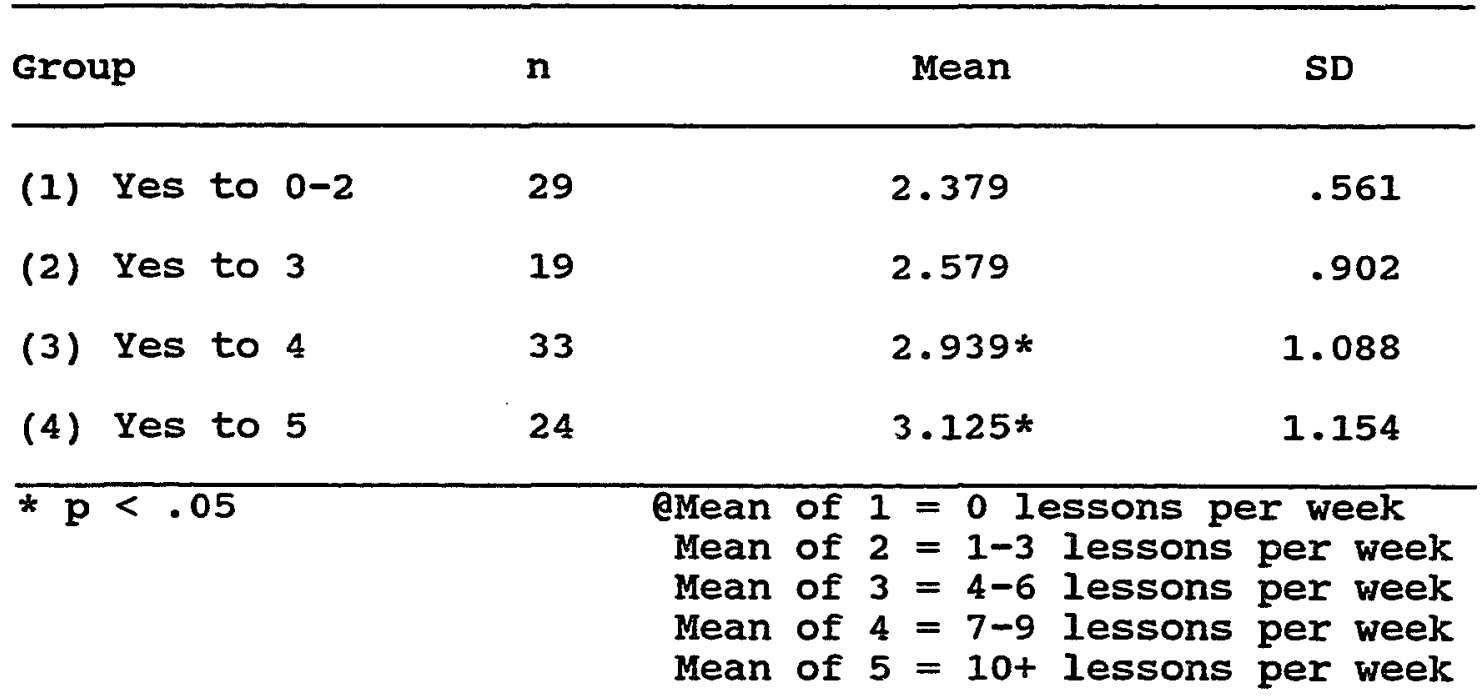

An analysis of variance, using amount of use as the dependent variable and number of skill maintenance opportunities as the independent variable was performed; aipha was set at .05. The statistical hypothesis that there would be no significant differences between the use per week 
means of the four groups $\left(H: M_{1}=M_{2}=M_{3}=M_{4}\right)$ was rejected $(p<.05)$. Table XXXVIII presents the analysis of variance.

TABLE XXXVIII

ANOVA BETWEEN NUMBER OF SKILL MAINTENANCE

OPPORTUNITIES AND USE PER WEEK

\begin{tabular}{|c|c|c|c|c|c|}
\hline Variable & $\begin{array}{l}\text { Source of } \\
\text { Variation }\end{array}$ & $\begin{array}{l}\text { Sum of } \\
\text { Squares }\end{array}$ & DF & $\begin{array}{l}\text { Mean } \\
\text { Square }\end{array}$ & $\mathbf{F}$ \\
\hline \multicolumn{6}{|l|}{$\begin{array}{l}\text { Number of skill } \\
\text { maintenance }\end{array}$} \\
\hline \multirow[t]{2}{*}{ opportunities } & $\begin{array}{l}\text { Between } \\
\text { within }\end{array}$ & $\begin{array}{r}9.085 \\
91.963\end{array}$ & $\begin{array}{r}3 \\
101\end{array}$ & $\begin{array}{r}3.028 \\
.911\end{array}$ & $3.326 *$ \\
\hline & Total & 101.048 & 104 & & \\
\hline
\end{tabular}

Further analysis, using the Fisher test, was conducted to see which pairs of the means differed significantly at alpha $=.05$. The following pairs of use per week means were tested: $\quad \overline{\mathrm{X}}_{1}-\overline{\mathrm{X}}_{2} ; \overline{\mathrm{X}}_{1}-\overline{\mathrm{X}}_{3} ; \overline{\mathrm{X}}_{1}-\overline{\mathrm{X}}_{4} ; \overline{\mathrm{X}}_{2}-\overline{\mathrm{X}}_{3} ;$ and $\overline{\mathrm{X}}_{2}-\overline{\mathrm{X}}_{4} \cdot \mathrm{A}$ significant difference was found between $\bar{X}_{1}-\bar{X}_{3}$ and $\bar{x}_{1}-\bar{x}_{4}$ as presented in Table XXXIX. 
TABLE XXXIX

FISHER TEST FOR NUMBER OF SKIIL MAINTENANCE OPPORTUNITIES AND AMOUNT OF USE

\begin{tabular}{llc}
\hline Group & Comparison & Fisher \\
\hline$\overline{\mathrm{X}}_{1}-\overline{\mathrm{X}}_{2}$ & Yes to $0-2$ vs Yes to 3 & .559 \\
$\overline{\mathrm{X}}_{1}-\overline{\mathrm{X}}_{3}$ & Yes to $0-2$ vs Yes to 4 & $.482 *$ \\
$\overline{\mathrm{X}}_{1}-\overline{\mathrm{X}}_{4}$ & Yes to $0-2$ vs Yes to 5 & $.522 *$ \\
$\overline{\mathrm{X}}_{2}-\overline{\mathrm{X}}_{3}$ & Yes to 3 vs Yes to 4 & .545 \\
$\overline{\mathrm{X}}_{2}-\overline{\mathrm{X}}_{4}$ & Yes to 3 vs Yes to 5 & $.581 *$ \\
$\bar{*}^{*}$ Significant at .05 level
\end{tabular}

The data in Table XXXVII are presented here in graph form.

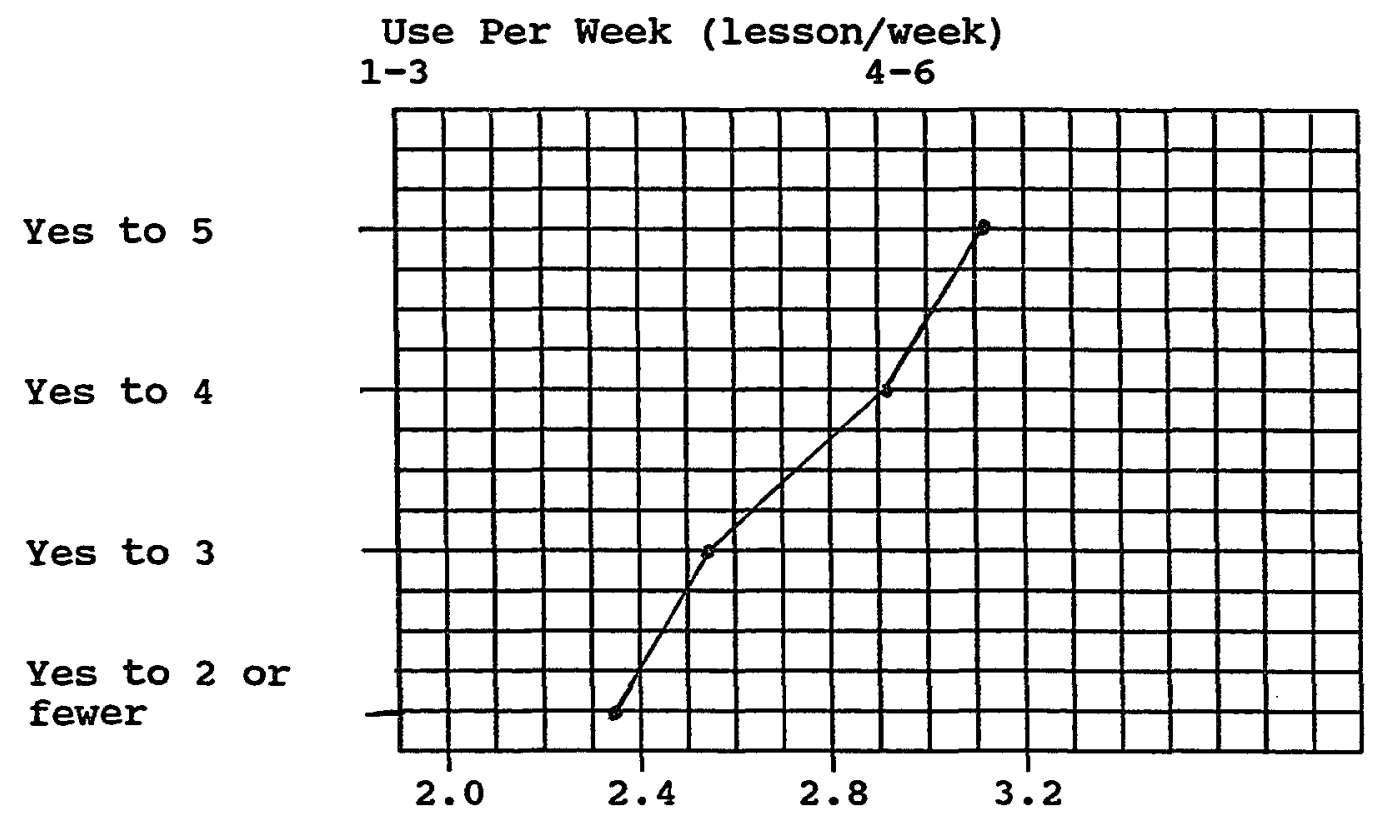

Figure 2. Graph showing opportunities for skill maintenance and use of cooperative learning per week. 
Item 15 was also analyzed in terms of each item and its relationship to amount of use of cooperative learning in the classroom. Table XL which presents a summary of the findings.

TABLE XL

$$
\begin{gathered}
\text { SUMMARY OF SIGNIFICANT COMPARISONS BETWEEN SKILL } \\
\text { MAINTENANCE OPPORTUNITIES AND } \\
\text { AMOUNT OF USE }
\end{gathered}
$$

Opportunity for skill Maintenance
Significant Relationship with Use

A. Discussion with colleagues

No

B. Peer coaching and feedback

No

C. Staff meeting discussions

Yes*

D. Principal observations and feedback

Yes*

E. Assistance from staff development personnel Yes* $* \mathrm{p}<.05$

The three maintenance opportunities which are significantly related to greater use of cooperative learning are: (a) staff meeting discussion, (b) principal observation and feedback, and (c) assistance from staff development personnel. The findings support the literature which holds that it is shared language which drives innovation and maintains momentum and interest (Little, 1982; Rosenholtz, 1989). During a staff meeting, instructional procedures may be talked about in the form of 
opinions, testimonials, and questions. The discussion generates both commitment and confidence to continue implementation of new methods. Principal observation and feedback sustains motivation and encourages more even participation of staff members in the application of new techniques.

The most powerful skill maintenance opportunity among the five for increasing the use of cooperative learning is assistance from staff development personnel $(p=.0036)$. This significant relationship makes a strong case for the role of staff development personnel not only as instructors of teachers, but as coaches during early implementation after formal training is over. Among the 106 respondents who reported yes to training in cooperative learning in this study, 85 reported having been trained by district personnel. Among the 85, 79\% responded yes to assistance from staff development personnel as one opportunity used to maintain skills.

An analysis of variance, using amount of use per week as the dependent variable and staff meeting discussion as the independent variable was performed. The statistical hypothesis that there would be no significant difference between the use per week means $\left(H: M_{1}=M_{2}\right)$ was rejected ( $p<$ .05). Table XII presents the group means on use per week for teachers who did and those who did not report staff meeting discussion. 
TABLE XLI

ITEM 15C: STAFF MEETING DISCUSSION AND USE PER WEEK

\begin{tabular}{lccc}
\hline Group & $\mathrm{n}$ & Mean & SD \\
\hline $\begin{array}{l}\text { No to staff meeting } \\
\text { discussion }\end{array}$ & 35 & 2.429 & .608 \\
$\begin{array}{l}\text { Yes to staff meeting } \\
\text { discussion }\end{array}$ & 70 & 2.929 & 1.094 \\
\hline
\end{tabular}

Table XIII presents the analysis of variance between staff meeting discussion and use per week.

TABLE XIII

ANOVA FOR 15C: STAFF MEETING DISCUSSION AND USE PER WEEK

\begin{tabular}{|c|c|c|c|c|c|}
\hline Variable & $\begin{array}{l}\text { Source of } \\
\text { Variation }\end{array}$ & $\begin{array}{l}\text { Sum of } \\
\text { Squares }\end{array}$ & DF & $\begin{array}{l}\text { Mean } \\
\text { Square }\end{array}$ & $\mathbf{F}$ \\
\hline \multirow[t]{2}{*}{$\begin{array}{l}\text { staff meeting } \\
\text { discussion }\end{array}$} & $\begin{array}{l}\text { Between } \\
\text { within }\end{array}$ & $\begin{array}{r}5.833 \\
95.214\end{array}$ & $\begin{array}{r}1 \\
103\end{array}$ & $\begin{array}{r}5.833 \\
.924\end{array}$ & $6.31 *$ \\
\hline & Total & 101.048 & 104 & & \\
\hline
\end{tabular}

An analysis of variance, using amount of use per week as the dependent variable and principal observation and feedback as the independent variable was performed. The statistical hypothesis that there would be no significant difference between the use par week means $\left(\mathrm{H}: \mathrm{M}_{1}=\mathrm{M}_{2}\right)$ was 
rejected $(p<.05)$. Table XLIII presents the group means on use per week for teachers who did and those who did not report principal observation and feedback.

TABLE XLIII

ITEM 15D: PRINCIPAL OBSERVATION/FEEDBACK AND USE PER WEEK

\begin{tabular}{lccc}
\hline Group & $\mathrm{n}$ & Mean & SD \\
\hline $\begin{array}{l}\text { No to staff principal } \\
\text { observation/feedback }\end{array}$ & 26 & 2.385 & .571 \\
$\begin{array}{l}\text { Yes to principal } \\
\text { observation/feedback }\end{array}$ & 79 & 2.886 & 1.062 \\
\hline
\end{tabular}

Table XLIV presents the analysis of variance between principal observation and feedback and use per week.

TABLE XLIV

ANOVA FOR 15D: PRINCIPAL OBSERVATION/ FEEDBACK AND USE PER WEEK

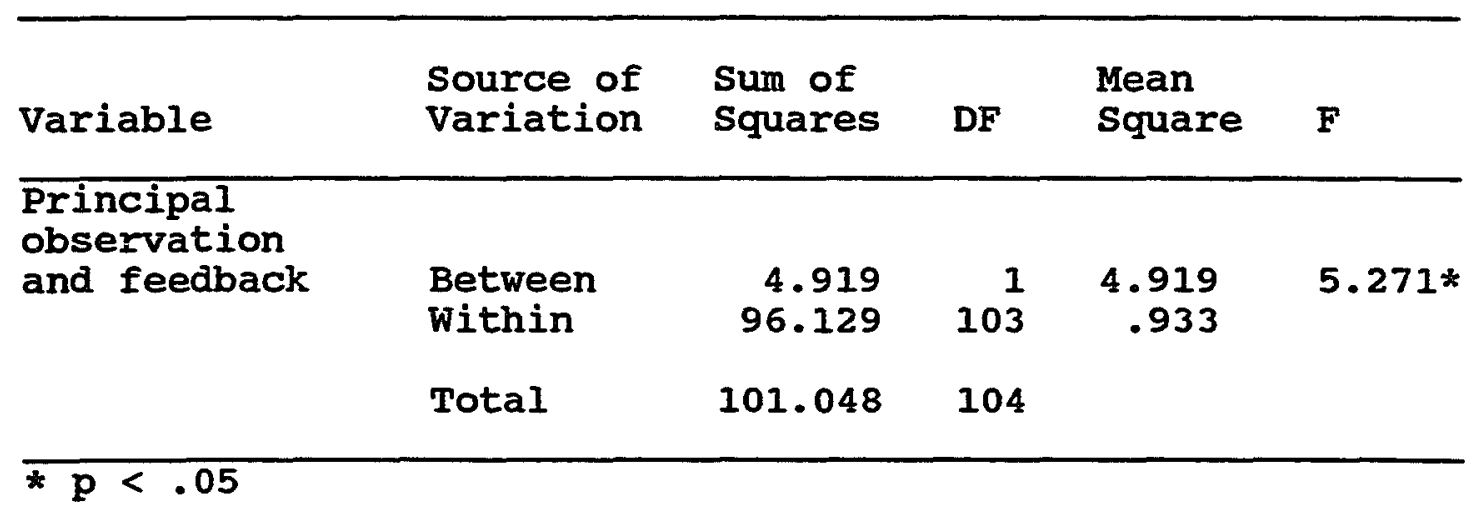

An analysis of variance, using amount of use per week as the dependent variable and assistance from staff 
development as the independent variable was performed. The statistical hypothesis that there would be no significant difference between the use per week means $\left(H: M_{1}=M_{2}\right)$ was rejected $(p<.05)$. Table XIV presents the group means on use per week for teachers who did and those who did not report assistance from staff development personnel.

TABLE XLV

ITEM 15E: ASSISTANCE FROM STAFF DEVELOPMENT PERSONNEL AND USE PER WEEK

\begin{tabular}{llll}
\hline Group & $\mathrm{n}$ & Mean & SD \\
\hline No to assistance & 38 & 2.395 & .718 \\
Yes to assistance & 67 & 2.97 & 1.058 \\
\hline
\end{tabular}

Table XLVI presents the analysis of variance between assistance from staff development and use per week.

TABLE XLVI

ANOVA FOR 15E: ASSISTANCE FROM STAFF DEVELOPMENT PERSONNEL AND USE PER WEEK

\begin{tabular}{|c|c|c|c|c|c|}
\hline Variable & $\begin{array}{l}\text { Source of } \\
\text { Variation }\end{array}$ & $\begin{array}{l}\text { Sum of } \\
\text { squares }\end{array}$ & DF & $\begin{array}{l}\text { Mean } \\
\text { Square }\end{array}$ & $\mathbf{F}$ \\
\hline \multirow[t]{2}{*}{$\begin{array}{l}\text { Assistance } \\
\text { from staff } \\
\text { development } \\
\text { personnel }\end{array}$} & $\begin{array}{l}\text { Between } \\
\text { Within }\end{array}$ & $\begin{array}{r}8.028 \\
93.019\end{array}$ & $\begin{array}{r}1 \\
103\end{array}$ & $\begin{array}{r}8.028 \\
.903\end{array}$ & $8.89 *$ \\
\hline & Total & 101.048 & 104 & & \\
\hline
\end{tabular}


SUMMARY OF THE FINDINGS

Research Questions 1A,

IB, and $1 C$

Do teachers trained in cooperative learning have a higher level of overall job satisfaction, collegiality, and efficacy than teachers who have not had training?

No significant differences were found in mean scores on collegiality, efficacy, or job satisfaction between teachers who experienced training in cooperative learning and those who did not experience training. This finding was true even when amount of training was considered; mean scores did not vary significantly as a function of number of hours of training.

Research Questions $2 A_{\text {, }}$ 2B, and 2C

Is there a significant relationships between variables in training and level of collegiality, efficacy, and job satisfaction?

A second purpose of the research was to examine how levels of collegiality, efficacy, and job satisfaction vary as a function of the following training variables:

1. setting

2. amount of use

3. kind of training

4. preparation for implementation

5. opportunity for skill maintenance 
No significant differences in mean scores were found to be associated with two of the training variables, setting and preparation for implementation. The other three training variables were found to be associated with either collegiality, efficacy, or job satisfaction. While association does not indicate causality, the strength of the association points to a relationship.

Training Variable 2: Amount of Use. Teachers who use cooperative learning seven or more times per week report significantly higher efficacy than those who use it four to six times per week.

Training Variable 3: Kind of Training. Where there was group sharing and problem solving during training, item 13C, teachers report both higher efficacy and job satisfaction. This finding, although based on a small number of respondents in the no category, suggest that group sharing and problem solving is an important part of training.

\section{Training Variable 5: Opportunity for Skill}

Maintenance. This training variable was associated with collegiality, efficacy, and overall job satisfaction. Teachers who use five opportunities to maintain skills, as opposed to three or fewer, report significantly higher collegiality and overall job satisfaction. Where there was peer coaching, item 15B, teachers have higher collegiality and job satisfaction. Two of the skill maintenance 
opportunities are associated with significantly higher efficacy: 15A, discussion with colleagues, and 15D, principal observation and feedback.

Training Variable 2: Amount of Use Compared to other Training Variables. Teachers who use cooperative learning in seven or more lessons per week report higher efficacy than those who use it less than that amount. With efficacy associated with greater use, it becomes important to look at the training variables which are related to frequency of implementation in the classroom. A total of seven training variables are associated with greater use of cooperative learning. They are:

1. Teachers who experienced four or five of the training components in item 13 reported significantly greater use than those who experienced three or fewer training components.

2. Item 13E, feedback from a qualified observer during early implementation was associated with greater use.

3. Teachers who report being extremely well prepared to implement sooperative learning in the classroom in item 14 also reported greater use than those who were moderately or fairly prepared.

4. Teachers who report the use of four or five opportunities to maintain skills, as opposed to the use of three or fewer, also report greater use of cooperative learning at a significant level. 
5. Item $15 \mathrm{C}$, the use of staff meeting discussion to maintain skills is associated with higher use at a significant level.

6. Item 15D, the use of principal observation and feedback to maintain skills is associated with higher use at a significant level.

7. Item 15E, assistance from staff development personnel to maintain skills is associated with higher use at a significant level.

\section{SUMMARY OF RESULTS}

The findings show that amount (number of hours) of training in cooperative learning was not associated with either job satisfaction or the subsets of collegiality and efficacy. However, the presence of certain training variables was found to be significant. Teachers who experienced these training variables in their cooperative learning training also reported higher job satisfaction, collegiality, or efficacy as shown in Table XIVII. Item C in Table XIVII needs explanation. Teachers who used all five opportunities to maintain skills, as opposed to three or fewer, reported significantly higher collegiality and job satisfaction. The five skill maintenance items are (a) discussion with colleagues, (b) peer coaching and feedback, (c) staff meeting discussion, (d) principal observation and 
feedback, and (e) assistance from staff development

personnel.

TABLE XLVII

SUMMARY OF SIGNIFICANT COMPARISONS BETWEEN TRAINING

VARIABLES AND LEVELS OF COLLEGIALITY, EFFICACY AND JOB SATISFACTION

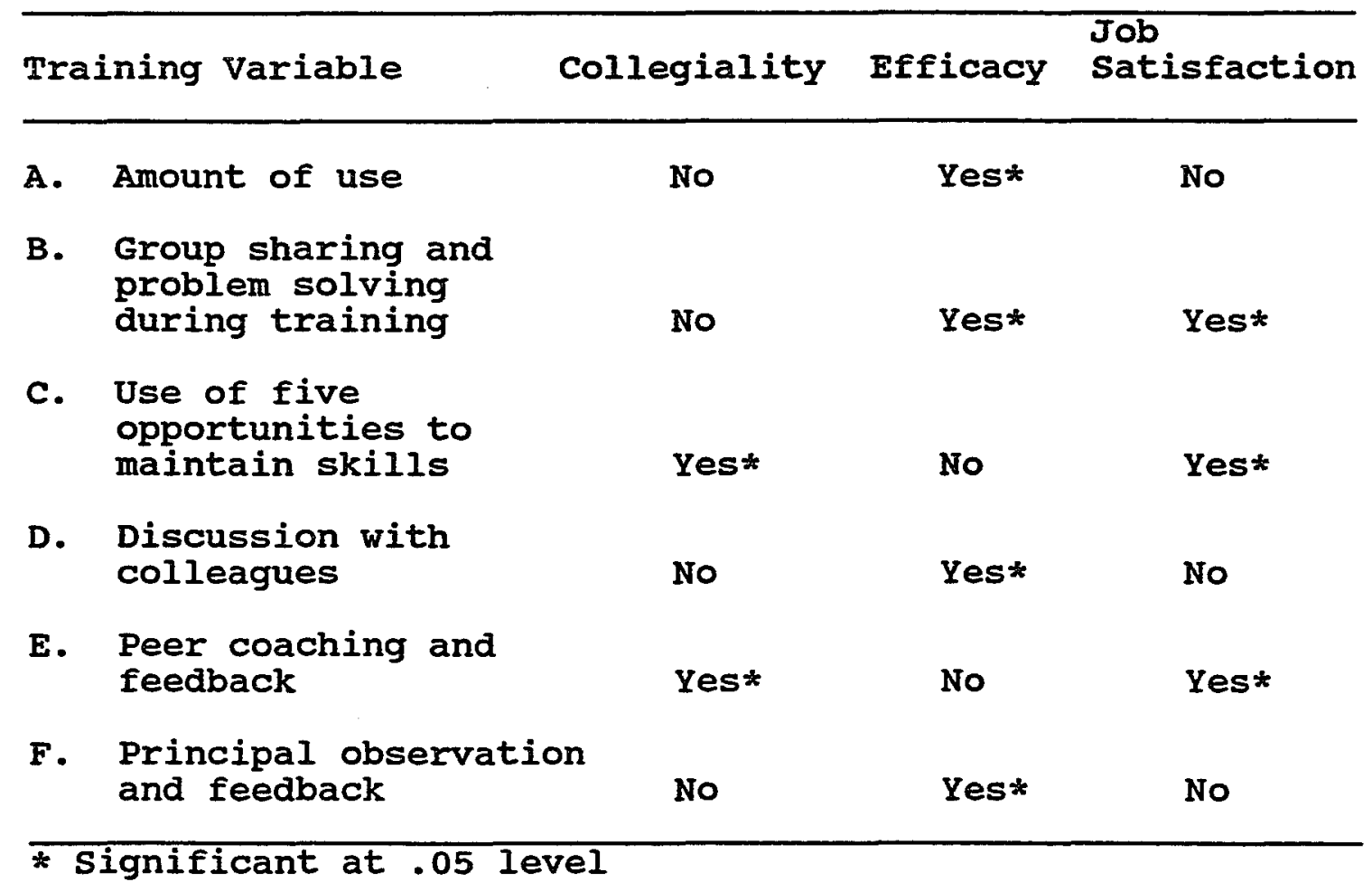




\begin{abstract}
CHAPTER V
SUMMARY, CONCLUSIONS, AND RECOMMENDATIONS
\end{abstract}

INTRODUCTION

\begin{abstract}
Chapter V contains summaries, conclusions, and recomnendations from the study. The following sections are presented in this chapter: (a) Summary of the study, (b) Conclusions, (c) Recommendations for Educational Practice, and (d) Recommendations for Further Research.
\end{abstract}

\title{
SUMMARY OF THE STUDY
}

The study was conducted in a suburban school district near Portland, Oregon where a staff training program in cooperative learning is well underway, but not as yet completed in all of the elementary schools. The district provided an opportunity to study a large sample of teachers with varying amounts and kinds of training in this specific area, cooperative learning. Additionally, the district encourages review and analysis of its programs. Several personnel are actively involved with instruction of both teacher and administrator course work in nearby colleges. During the 1988-1989 school year, the staff development department had provided cooperative learning training in 
approximately half of the elementary schools and was developing a calendar for on-site training in the remaining schools. Teacher feedback on the training which had been completed was sought so that modifications and additions could be made as the district proceeded with more training. The affective strategies of cooperative learning (i.e., helping, encouraging, teaming, and supporting in a collaborative setting) made this particular staff development topic of interest for its potential effect on the teachers themselves. The central purpose of the study was to analyze a possible association between training in cooperative learning and teacher job satisfaction, with special attention to the subsets of collegiality and efficacy. A second purpose was to examine how levels of job satisfaction, efficacy, and collegiality vary as a function of the following training variables: (a) setting, (b) amount of use, (c) kind of training, (d) preparation for implementation, and (e) opportunity for skill maintenance. The study was conducted by the use of a survey with 129 teachers responding, a response rate of $71 \%$. Participation was voluntary and the good return rate during the closing weeks of school may be an indication of staff willingness to reflect on training, interest in cooperative learning, and a general indication of district morale. The survey consisted of two sections. The first part collected data about the five training variables in cooperative 
learning. The second section was a 30-item Job Satisfaction Survey which included subscales of 10 questions on collegiality and 15 on efficacy. The remaining 5 questions pertained to overall job satisfaction. The validity of the Job Satisfaction survey was established by pilot testing, by expert review of the questions, and by the use of an established survey as a bench mark for comparison. The research analysis involved the examination of mean scores on the Job Satisfaction Survey and ANOVA techniques to examine the relationship between variables in training and levels of job satisfaction as well as teacher collegiality and efficacy.

The study was not intended to establish a causal link, but rather to identify a possible significant relationship between training in cooperative learning and teacher job satisfaction. Although the findings did not support this research hypothesis, a significant relationship was found between several training variables and level of satisfaction, collegiality, and efficacy.

\section{Teacher Efficacy}

An important finding is the positive association between frequent use of cooperative learning in the classioom and higher teacher efficacy. With efficacy defined as the teacher characteristic with the most consistent relationship to student achievement (Ashton, 
1984), this positive association is noteworthy, and supported by statistical evidence in the study. The training components which were found to be significantly associated with teacher efficacy are as follows: (a) amount of use at the level of seven or more times per week, (b) small group sharing and problem solving sessions for participants during training, (c) the use of discussion with colleagues to maintain skills, and (d) the use of principal observation and feedback to maintain skills. These four training variables can easily be included in structuring staff development opportunities. Given the results of this study, staff development specialists and inservice organizers should structure training to conform to these significant variables.

\section{Teacher Collegiality}

Training variables which were found to be significantly associated with higher collegiality are as follows: (a) the use of five different opportunities to maintain skills as opposed to three or fewer and (b) the use of peer coaching and feedback to maintain skills. Therefore, the results of the study indicate the importance of follow-up after training, especially in the form of peer coaching and other collegial activities. The findings on peer coaching are particularly useful; although it has been advocated for over a decade, references to supporting 
research are lacking. In practice, administrators seem reluctant to initiate peer coaching, perhaps assuming teachers are unwilling to participate. The findings show that teachers look upon peer coaching as a welcome source of help and as a source of job satisfaction.

\section{Overall Job Satisfaction}

Overall job satisfaction was higher where there was:

(a) small group sharing and problem solving sessions during training, (b) the use of five skill maintenance opportunities as opposed to the use of three or fewer, and (c) the use of peer coaching and feedback to maintain skills. Principals, stafr development specialists, and other administrators are all aware of the importance of job satisfaction for effective teaching and learning. The study adds the important dimension of a research-based recommendation to provide these three training variables as an easily adopted means for improving and maintaining job satisfaction.

Implementation of new methods requires the support of a strong staff developmenti program. When new methods are ignored or sparingly used, even the most popular and wellfunded projects have little impact on staff or students and the chances for any growth in teacher satisfaction, collegiality, or efficacy is diminished. The study found seven training variables associated with greater application 
of cooperative learning; these take on special significance because of the finding that greater use of cooperative learning is associated with higher efficacy. The seven training variables found to be associated with greater use are: (a) variety in the components of training, (b) feedback from a qualified observer during early implementation, (c) extremely high quality preparation for implementation, (d) variety in skill maintenance opportunities, (e) staff meeting discussion, (f) principal observation and feedback, and ( $g$ ) assistance from staff development personnel.

\section{CONCLUSIONS}

Staff development is an important source of professional growth and building school norms which enhance teacher job satisfaction, as well as the subsets of teacher efficacy and collegiality. Carefully designed training programs are a means of bringing about reform and a more satisfying work environment. Although an association was not found between cooperative learning training and teacher job satisfaction, the present study advanced our understanding of efficacy and collegiality as well as overall satisfaction. In addition, several training variables were found to be associated with efficiay, collegiality, and overall satisfaction; training variables 
which can now be recommended on the basis of statistical evidence.

\section{Efficacy}

The association between greater use of cooperative learning and higher teacher efficacy is a key finding in the study; it is a finding which impacts teacher training. Teachers who use cooperative learning strategies with their students increase their own sense of efficacy. They themselves are empowered, feel more confident, and are more willing to attempt innovation. Efficacy must receive greater attention in all phases of teacher preparation. It needs to be developed and renewed through ongoing staff development. In addition to the technical skills of instruction, training must address the teacher's need for an outlook of hope and determination in the classroom. Other training variables which the study found to be associated with efficacy are small group sharing and problem solving sessions for participants during training, the use of discussion with colleagues to maintain skills, and the use of principal observation and feedback.

In her research on burnout in school administrators, Wax (1983) identified six factors related to job perseverance and success. One was the psycho-physical state which she defined as overall mental, emotional, and physical vigor and resilience. The definition is an excellent 
description of efficacy. While it remains an abstract quality, the current study made a significant step towards defining, quantifying, and measuring efficacy. Beyond preparation in the science of teaching, formulas and "howto" manuals, teachers need sources of encouragenent and hopefulness. The mental and emotional vigor of the teacher has to be a concern of educational leaders.

Teachers with high efficacy have a strong sense of personal power and causation; they tend not to accept student failure. The present study shows that where there was greater application of the cooperative model with its affective strategies of team building, communication skills, inclusiveness, and supportive interaction; teachers felt a stronger sense of hope, confidence, and causality. Any research which shows us how to increase efficacy, the importance of which was highlighted in this study, is of great value.

\section{Collegiality}

The literature review supported the observation by Lortie (1975) that teachers remain physically isolated and do not know each other as professional colleagues who can be relied upon for both technical assistance and emotional support. Among other professionals--medical doctors and actorneys for example--it is common practice to refer to colleagues for advice and opinions. The same practice of 
collaborating and pooling of knowledge is greatly needed in the field of education. Although the job of teachers is still very isolated, the problems in today's schools are compelling teachers to look for colleagues for technical help and emotional encouragement. As teaching becomes more complex, it is imperative that we reflect on our work, using lessons from the past to make corrections and thoughtful decisions for the future. The process of reflecting, brainstorming, and planning in a collegial setting generates one of the most powerful sources of job satisfaction, namely, the support and interaction among colleagues. The present study confirmed the need to provide collegial activities for teachers, not only during training but afterward, as a means of maintaining skills. Specifically, the findings provide evidence that staff development should include certain training variables: discussion with colleagues, peer coaching, staff meeting discussion, principal observation, and help from staff development personnel. Each is a collaborative effort and builds shared understandings, a common technical language, and a shared sense of obligation so that new strategies are actually put into practice. Collegial discussion, by using the resources from within, is a source of teacher strength and motivation.

An important conclusion can be drawn that training without feedback opportunities, especially peer coaching, is 
lacking a critically important element. Writing as recently as two years ago, Joyce and showers (1988) refer to peer coaching as an innovation still in the beginning stages, requiring a radical change in relationships between teachers in order to become common practice. A somewhat surprising finding in the current study is that teachers who experienced peer coaching also reported higher collegiality and job satisfaction. Peer coaching, as opposed to a formal administrative process of critiquing and correction, may increase satisfaction because it provides an opportunity to explore and discuss instruction with an empathetic colleague who has "been there." Additionally, it is a two-way process in which colleagues can coach each other, as opposed to the one-way process of administrator observation. The power of peer coaching is substantiated by this study as a practice which should be included in any staff development program.

\section{Overall Job Satisfaction}

In her study, Perko (1985) recommended further investigation of staff development as a source of developing teacher job satisfaction. While a great deal is written on the topic, there is a need for quantitative data; the current study adds the important dimension of research-based recommendations for increasing job satisfaction. The three training variables found to be associated with higher overall satisfaction [(a) small group sharing and problem 
solving sessions during training, (b) the use of skill maintenance opportunities, and (c) the use of peer coaching] all have a similar characteristic. Each of these training variables reduces the isolation of the teacher and increases collaboration. The conclusion can be drawn that the application of cooperative strategies such as helping, encouraging, teaming, and supporting make the job of teaching more satisfying and efficacious.

\section{RECOMMENDATIONS FOR EDUCATIONAL PRACTICE}

The association between teacher efficacy and use of cooperative learning has tremendous implications at all levels and in all subjects. This particular model with its essential feature of investment in the success of others has first to be understood and experienced by the teachers during their preparation. Among their own colleagues they must practice such skills as rotation of roles, group inclusiveness, conflict resolution, and team rather than individual recognition. Teachers who reported the greatest level of application of these cooperative skills with their students also reported higher efficacy. Individualistic and competitive models certainly have a place but cooperative learning needs to be part of every teacher's repertoire.

The findings provide research-based recommendations for the structure of both initial training and follow up 
activities in staff development. Several different training variables are recommended because of their association with efficacy, collegiality, or overall job satisfaction. small group sharing and problem solving sessions should be provided during inservice classes. After training classes are over, a variety of skill maintenance opportunities are needed. Discussion with colleagues at this stage contributes to efficacy; therefore, as a follow up to formal training there needs to be additional opportunities for teachers to work in a collegial setting. Principals need to make the classroom observation schedule a priority and more training needs to be done to increase the use of peer coaching. staff meeting discussions and assistance from staff development personnel are additionally recommended as sources of motivation, renewal, and refinement of skills. Awareness of significant training variables can make teachers better consumers as they select course work. Confronted with an ever increasing number of offerings presented in catalogues and brochures, written in urgent and persuasive language, the need for consumer discrimination is increasingly important. Courses are sometimes billed for their entertainment features or quick-fix approaches. Staff development, as pointed out in this study, is often a disappointment to individual teachers and to groups involved in schoolwide improvement efforts. The findings have generated a list of staff development training variables 
which can now be recommended on the basis of research which found them to be associated with job satisfaction, collegiality, and efficacy. When choosing course work, teachers can use this information as a guide to wise selections. The significant training variables (listed in Table XLVII) can be summarized very briefly as follows: (a) a great amount of practice with ongoing feedback for the purposes of correction and refinement of skills and (b) consistent professional interaction with colleagues to maintain skills through help and encouragement. This summary contrasts sharply to some course advertisements where the theme is ease, with no need for any serious time commitment and the promise of complete freedom from difficulties and failures.

Another implication for educational practice is the finding of seven training variables associated with greater application of cooperative learning in the classroom. Many educational reforms are never fully implemented and it is a great challenge for staff development specialists to actually get new methods into practice. Certain of the seven training variables, such as staff meeting discussion, small group discussion, and principal observation and feedback, can be easily included through the use of present resources. Others such as feedback during early implementation from a qualified observer and assistance from staff development personnel have implications for staffing. 
The rules of science do not permit a statistical inference of the findings of this study to be applied to other districts. However, a reasonable assumption (unproven, therefore not scientific) would be that the findings could have application in other districts that are comparable in size, location, and history of experience in staff development.

\section{RECOMMENDATIONS FOR FURTHER RESEARCH}

The investigation of teacher job satisfaction needs to continue. The data from this study suggest at least three areas in need of further research. One is the structure of staff development programs. With the finding that staff development can be a source of efficacy, collegiality, and satisfaction; the components and design of teacher inservice need further research. There may be other training variables, omitted in this study, which contribute to job satisfaction.

Secondly, there is an important need to study peer coaching especially in light of the findings of this particular research project in which teachers report it to be highly beneficial. Research should be conducted to investigate successful models and resolve the question of why there is a reluctance to implement peer coaching. Finally, it is recommended that the Job satisfaction Survey be replicated with other staff development topics 
such as ITIP (instructional theory into practice), learning styles, and classroom management classes. Further use would lead to better understanding of the association between staff training and the development of efficacy, collegiality, and satisfaction. In repeating the study, it would be important to examine comparisons between training variables and amount of use since it is the application of any method that is fundamental to impact on students and teachers.

\section{Replication of the study}

Along with the recommendation to replicate the entire study, at least four modifications should be considered in the design. First, the study should be conducted in varied school settings such as small rural and large urban areas. It should also be used at the middle and high school levels where efficacy and collegiality are greatly needed for teacher confidence and commitment. The present investigation was conducted in a highly satisfied teacher population at the elementary level. In addition, the respondents were classroom teachers. Support personnel such as physical education and remedial reading teachers were not included; this group of teachers may have contributed data which would have altered the findings. Replication of the study with varied teacher populations would serve to verify the findings and perhaps refine the survey instruments. 
A second improvement would be to find a situation in which a group of staff members was experiencing concentrated staff development in cooperative learning only, with other major inservice topics excluded for a period of time. The objective would be to prevent the findings from being confounded by other training in the same time period and to isolate cooperative learning as the only formal staff development effort during the investigation.

Another important consideration is the set of questions on collegiality in the Job Satisfaction Survey. There are 10 collegiality questions. Seven asked about relationships with the entire school staff and three asked about relationships with one other teacher or within a group or team. There is an important distinction. It is fairly common for teachers to have strong collegial ties with one peer or within a very small segment of a staff but be notably lacking in professional association with the remainder of the group. The absence of collegiality throughout the entire staff is a significant problem because needed interaction among teachers of different grades and subjects does not occur. Small cliques may be collegial but remain isolated and actually protect members from mixing with the rest of the faculty. Although not specifically planned in advance, the balance of questions, that is, three on peer or small group collegiality and seven on entire staff relations, seems appropriate. In replicating the 
study, it would be useful for the researcher to be aware of this pattern.

Finally, it is recommended that every effort be made to generate a higher response rate when replicating the study. When a number of teachers elect not to respond, the data base is less accurate. In this study the response rate was high (71\%). It is impossible to know if the nonparticipating teachers are, in general, dissatisfied teachers who chose not to bother with a survey or if they are very satisfied and have no compelling reason to fill out a survey. Those who do not respond leave unanswered questions; the research would be strengthened by $a$ participation rate of $90 \%$. 


\section{REFERENCES}

Adams, B., \& Bailey, G. (1989). School is for teachers: Enhancing the school environment. National Association of Secondary school Principals Bulletin, $\underline{73}(513), 44-48$.

Apple, R. W. Jr. (1989, January 21). Nation stands ready to push on. The New York Times, p. I 10:1.

Ashton, P. (1984). Teacher efficacy: A motivational paradigm for effective teacher education. Journal of Teacher Education, XXXV(5), 28-32.

Ashton, P., \& Webb, R. (1986). Making a difference: Teachers' sense of efficacy and student achievement. White Plains, NY: Longman.

Ashton, P., Webb, R., \& Doda, N. (1983). A study of teachers' sense of efficacy: Final report. Gainesville, FL: National Institute of Education.

Berliner, D. C. (1986). Introduction. In P. Ashton, and R. Webb, Making a difference: Teachers' sense of efficacy and student achievement (pp. xii). White Plains, NY: Longman.

Bloom, B. (1978). New views of the learner: Implications for instruction and curriculum. Educational Leadership, 35(7), 563-576.

Brandt, R. (1978) . Is cooperation un-American? Educational Leadership, $45(3), 31$.

Brookover, W. B., Beamer, L., Efthim, H., Hathaway, D., Lezotte, L., Miller, S., Passalacqua, J., \& Thornatzky, L. (1982) . Creating effective schools. Holmes Beach, FL: Learning Publications.

David, J. (1989). Synthesis of research on school-based management. Educational Leadership, 46(8) 45-53.

Deal, T. (1984). Educational change: Revival tent, tinkertoys, jungle, or carnival? Education Change, 86 (1), 124-137. 
Dembo, M. \& Gibson, S. (1985). Teachers' sense of efficacy: An important factor in school improvement. Elementary School Journal, 86(2), 178-184.

Duke, D. (1984). Teaching: The imperiled profession. Albany, NY: State University of New York Press.

Fullan, M. (1982). The meaning of educational change. New York: Teachers College Press.

Fuller, B., Wood, K., Rapoport, T., \& Dornbusch, S. (1982). The organizational context of individual efficacy. Review of Educational Research, 52(1), 7-30.

Gecas, V., \& Schwalbe, M. (1983). Beyond the looking glass self: Social structure and efficacy-based selfesteem. Social Psychology Quarterly, 46(2), 77-88.

Gibson, S., \& Dembo, M. (1984). Teacher efficacy: A. construct validation. Journal of Educational Psychology, 76(4), 569-582.

Glasser, W. (1986). Control theory in the classroom. New York: Harper and Row.

Graves, N. E., \& Graves, T. D. (1985). Creating a cooperative learning environment. In R. Slavin, s. Shlomo, S. Kagan, R. Lazarowitz, C. Webb, \& R. Schmuck (Eds.), Learning to cooperate, cooperating to learn (pp. 403-436). New York: Plenum Press.

Gruneberg, M. (1979) - Understanding job satisfaction. London: MacMillan.

Guskey, T. (1986). Staff development and the process of teacher change. Educational Research, 15(5), 5-15.

Hersh, R. H. (1985) - Organizational efficacy as a research focus for school improvement. In National center for Education Statistics (Ed.), Invited papers:

Elementary/secondary education data redesign project (pp. 232-246) . Washington, DC: National Center for Education statistics.

Herzberg, F. (1987). Innovation: Where is the relish? The Journal of Creative Behavior, 21(3), 179-192.

Johnson, D. W., \& Johnson, R. T. (1980). The key to effective inservice: Building teacher-teacher collaboration. The Developer. Oxford, $\mathrm{OH}$ : National Staff Development Council. 
Johnson, D. W., Johnson, R. T., \& Holubec, E. J. (1988) . Cooperation in the classroom. Edina, MN: Interaction Book Company.

Johnson, D. W., Johnson, R. T., Holubec, E. J., \& Roy, P. (1984). Circles of learning. Alexandria, VA: Association for Supervision and Curriculum Development.

Johnson. R. T., \& Johnson, D. W. (1982) . Cooperation in learning: Ignored but powerful. Lyceum, 5, 22-26.

Joyce, B., Hersh, R. \& Mckibbin, M. (1983). The structure of school improvement. White Plains, NY: Longman.

Joyce, B., \& Showers, B. (1988). Student achievement through staff development. White Plains, NY: Longman.

Kagan, S. (1985). Learning to cooperate. In R. Slavin, S. Shlomo, S. Kagan, R. Lazarowitz, C. Webb, \& R. Schmuck (Eds.), Learning to cooperate, cooperating to learn (pp. 365-369). New York: Plenum Press.

Kreis, K., \& Brockopp, D. (1986). Autonomy: A component of teacher job satisfaction. Education, 107(1), 110115 .

Leslie, K. (1989). Administrators must consider and improve teacher job satisfaction. National Association of secondary School Principals Bulletin. 73(513), 19-22.

Lester, P. E. (1987). Development and factor analysis of the teacher job satisfaction questionnaire (TJSD2). Educational and Psychological Measurement, 47(1), 223233 .

Little, J.W. (1982). Norms of collegiality and experimentation: Workplace conditions of school success. American Educational Research Journal, $19(3), 325-340$.

Lortie, D. C. (1975) . Schoolteacher. Chicago: The University of Chicago Press.

Maloy, R., \& Jones, B. (1987). Teachers, partnerships, and school improvement. Journal of Research and Development in Education, 20(2), 19-24.

National study of School Evaluation. (1981). Teacher opinion Inventory. Falls Church, VA: Author. 
Perko, I. L. (1985). Job satisfaction of teachers in the Portland metropolitan area: An examination of differing factors and their relationship to Herzberg and Lortie theories (Doctoral dissertation, Portland State University, 1985). Dissertation Abstracts International, 65, 1590A. (University Microfilms No. AD D85-17640)

Rosenholtz, S. (1985). Effective schools: Interpreting the evidence. American Journal of Education, 93(3), 352-388.

Rosenholtz, S. (1987). Education reform strategies: will they increase teacher commitment? American Journal of Education, 95(4), 534-562.

Rosenholtz, S. (1989). Teachers' workplace: The social organization of schools. New York: Longman.

Scott-Miller, S. (1984). An investigation of the relationship between biographical characteristics and job satisfaction among middle school teachers in four suburban districts. (Doctoral dissertation, Portland State University, 1984). Dissertation Abstracts International, 46, 01. (University Microfilms No. AD D85-05922)

Sergiovanni, T. J. (1984). Handbook for effective department leadership (2nd ed.). Newton, MA: Allyn and Bacon.

Slavin, R. E. (1982) . Cooperative learning: student teams. Washington, DC: National Education Association of the United States.

Slavin, R. E. (1984). Research methods in education: A practical quide. Englewood Cliffs, NJ: PrenticeHall.

Slavin, R. E. (1985). An introduction to cooperative learning research. In $R$. Slavin, S. Shlomo, $S$. Kagan, R. Lazarowitz, C. Webb, \& R. Schmuck (Eds.), Learning to cooperate, cooperating to learn (pp. 515). New York: Fienum Press.

Smylie, M. (1988). The enhancement function of staff development: organizational and psychological antecedents to individual teacher change. American Educational Research Journal, 25(1), 1-30. 
Solomon, D., Watson, M. , Battistich, B., Schaps, E. , Tuck, P., Solomon, J., Cooper, C., \& Ritchey, W. (1985). program to promote interpersonal consideration and cooperation in children. In R. Slavin, S. Shlomo, S. Kagan, R. Lazarowitz, C. Webb, \& R. Schmuck (Eds.), Learning to cooperate, cooperating to learn (pp. 371401). New York: Plenum Press.

Sparks, G. (1983). Synthesis of research on staff development for effective teaching. Educational Leadership, 41(3), 65-72.

Sparks, G. (1988). Teachers' attitudes toward change and subsequent improvements in classroom teaching. Journal of Educational Psychology, 80(1), 111-117.

Towson, S. (1985) . Melting pot or mosaic. Cooperative education and interethnic relations. In $R$. Slavin, S. Shloms; S. Kagan, R. Lazarowitz, C. Webb, \& R. Schmuck (Eds.), Learning to cooperate, cooperating to learn (pp. 263-276). New York: Plenum Press.

Trentham, L., Silvern, S., \& Brogdan, R. (1985). Teacher efficacy and teacher competency rating. Psychology in the Schools, 22(3), 343-352.

Wax, A. (1983). An investigation of the reliability, subscale intercorrelations, and validity of the administrator role perception inventory. (Doctoral dissertation, Portland State University, 1983). Dissertation Abstracts International), 46, 01 . (University Microfilms No. AD D83-17611) 
APPENDIX A

SURVEY INSTRUMENTS 
DATE: MaY 8, 1989

TO: Participating Teachers

FROM: Margaret Dutton, Portland state student

RE: The enclosed survey instruments

The enclosed survey instrument is being sent to you as part of a district-approved external research project being conducted for a doctoral dissertation at portland state.

The purpose of the research is to (1) investigate the relationship between level of job satisfaction and training in cooperative learning, and (2) identify variables in the design of inservice which may impact job satisfaction.

The study seeks to obtain the views of you, the practitioner, and your perceptions to improve staff development programs. All individual responses are confidential and anonymous. Participation is voluntary. The overall results will be made available to the district.

All classroom teachers of kindergarten through grade six are asked to respond. Please complete both Part I and Part II of the survey.

Feel free to call me if you have questions; I can be reached at 678-5835 or 692-0276. If you wish to call the office of Grants and contracts, the number is 464-3417 at Portland state University.

Thank you so much for your time and cooperation. When you finish with your responses, seal the survey in the envelope provided and return it to the large collection envelope located in a designated area of your school office--WITHIN FIVE DAYS. If you choose not to respond, please return the blank survey in a sealed envelope. The sealed envelopes will be collected by the researcher. 
Background Information

Directions

\section{PART I}

Circle the letter of the appropriate response to the following information about you.

1. Gender
A. Female
B. Male

2. Age (at last birthday)
A. 20-29
B. $30-39$
C. $40-49$
D. 50-59
E. $60+$

3. Highest earned academic degree
A. Bachelor's
B. Master's
C. Doctorate

4. Total years in teaching
A. $0-9$
B. 10-19
C. 20-29
D. $30+$

4a. Which level have you taught for the last two years?
A. Primary (grades $\mathrm{K}-3$ )
B. Intermediate (grades 4-6)
C. Both levels

5. How many graduate level credits have you earned in the past two years, 1987 and 1988?
A. None
B. 1-3
C. 4-6
D. 7 or more 
6. In which of these areas have you had training? Please check YES or No for each item.

YES NO
A.
B. Computer use.......................
c. Peer coaching......................
D. Learning styles.
E. Gifted education
F. Class management.
G. Cooperative learning.

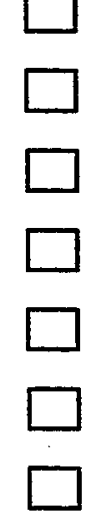
If you marked YES on cooperative learning in question 6 , please complete the next section through question 15.

7. How many clock hours of training in cooperative learning have you had in the past two years?
A. 1-5 hours
B. 6-10 hours (10 hours is equivalent to 1 credit)
C. 11-15 hours
D. 16-20 hours (20 hours is equivalent to 2 credits)
E. 21-25 hours
F. 26-30 hours ( 30 hours is equivalent to 3 credits)

8. Which setting describes how you took most of your training in cooperative learning?
A. In workshops with no college credit
B. In classes with college credit

9. Which setting describes where you took most of your training in cooperative learning?

A. With a team of my school or district colleagues

B. Not with a team of my school or district colleagues

10. Did your principal take cooperative learning with you?
A. Yes
B. No 
11. Who were you primarily trained by in cooperative learning?
A. District personnel only
B. Most district personnel
C. Mostly out-of-district personnel
D. All our-of-district personnel

12. In how many lessons per week, on the average, do you use cooperative learning with your students?
A. None
B. In 1-3 lessons per week
C. In 4-6 lessons per week
D. In 7-9 lessons per week
E. In 10 or more lessons per week

13. What kind of training did you receive in the class or workshop where you took most of your training. check YES or No for each item.

YES NO

A. Were the theories and research that support cooperative learning presented?...

B. Was there modeling and demonstrating of cooperative learning methods by the

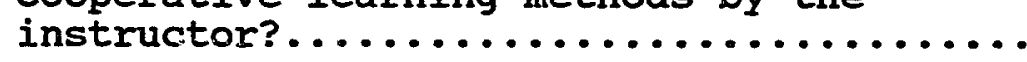

C. Were there small group sharing and problem solving sessions for participants?.

D. As students, did you do cooperative learning activities in the class or workshop?.

E. Did you receive feedback from a qualified observer as you tried the new techniques in your own classroom?................

14. How well did your training prepare you to implement cooperative learning in your classroom?

A. Extremely well

B. Very Well

C. Moderately well

D. only fairly well

E. Not well 
15. What opportunities do you use to maintain your skills in cooperative learning? Check YES or NO for each item.

YES NO

A. Discussion with colleagues............ $\square \square$

B. Peer coaching and feedback...............

C. Staff meeting discussion..............

D. Principal observation and feedback........

E. Assistance from staff development personnel......................... 


\section{PLEASE NOTE:}

Copyrighted materials in this document have not been filmed at the request of the author. They are available for consultation, however, in the author's university library.

These consist of pages:

Job Satisfaction Survey 131-137

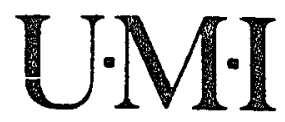




\section{APPENDIX B}

CORRESPONDENCE 


\section{HUMAN SUBJECTS RESEARCH \\ REVIEW COMMITTEE}

\section{MEMORANDUM}

OFFICE OF GRANTS AND CONTRACTS

May 5, 1989

TO: Margaret Dutton, ED/ADMIN

FROM: Dean Frost, Chair, HSRRC

RE: HSRRC approval of your application

In accordance with your request, the Huran Subjects Research Review Committee has reviewed your application ("The Relationship Between Training in Cooperative Learning and Teacher Job Satisfaction") for compliance with Department of Health and Human Services policies and regulations on the protection of human subjects.

The committee is satisfied that your provisions for protecting the rights and welfare of all subjects participating in the research are adequate. Your application will be listed in our files as approved.

DF:jp 


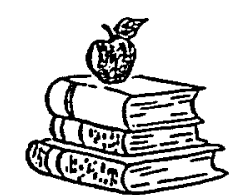

\title{
NORTH MARION ELEMENTARY SCHOOL
}

\author{
20237 Grim Road N.E. • Aurora, Oregon 97002 • 678-5835/982-9887 \\ Margaret Dutton \\ Principal
}

February 15, 1989

\author{
- Assistant Superintendent, Curriculum \\ School District \\ , Oregon
}

Dear

:

This letter is a request for your consideration of an educational research project in the schools during spring term. I am writing' my doctoral dissertation in the field of educational administration through Portland State. The topic is cooperative learning and I would like your approval to conduct the research in the elementary schools of the Tigard district.

The specific purposes of the research are to (1) test the hypothesis that the job satisfaction level of teachers who have taken cooperative learning will exceed that of the teachers who have not had the training, and (2) identify the relationship between variables in inservice training and level of job satisfaction. The district offers a unique setting for this study because approximately half of the schools have recently had cooperative learning inservice. Therefore, there is a large sample size of teachers who have experienced, and who have not experienced the training.

The data would be collected on a survey (a copy is enclosed) which would be sent to all elementary teachers: the time needed for completion is about 20 to 30 minutes.

In order to proceed with the research, I would like to work with who will arcange for me to meet with building principals to explain the study. Shortly after that meeting, the surveys will be distributed. Confidentiality of the respondents and the schools will be carefully maintained and the identity of the district will not be disclosed in the report of the findings.

The method of dissemination and collection of the surveys is flexible and will be done with a minimum of interruption in the schools. 
If you have any questions, please contact me. I will look forward to hearing from you after you review the enclosed materials. I can be reached at school, 678-5835, or at home, 692-0276.

Thank you for your consideration of this request. I hope you will find it worthwhile for your district to participate.

Sincerely,

Theyaret dluttos

Margaret Dutton

MD:sd

enc. 